\title{
Wnt evolution and function shuffling in liberal and conservative chordate genomes
}

\author{
Ildikó M. L. Somorjai ${ }^{1,2^{*}}$, Josep Martí-Solans ${ }^{3}$, Miriam Diaz-Gracia ${ }^{3}$, Hiroki Nishida ${ }^{4}$, Kaoru S. Imai ${ }^{4}$, Hector Escrivà ${ }^{5}$, \\ Cristian Cañestro ${ }^{3^{*}}$ and Ricard Albalat ${ }^{3^{*}}$ (i)
}

\begin{abstract}
Background: What impact gene loss has on the evolution of developmental processes, and how function shuffling has affected retained genes driving essential biological processes, remain open questions in the fields of genome evolution and EvoDevo. To investigate these problems, we have analyzed the evolution of the Wnt ligand repertoire in the chordate phylum as a case study.

Results: We conduct an exhaustive survey of Wht genes in genomic databases, identifying 156 Wht genes in 13 non-vertebrate chordates. This represents the most complete Wht gene catalog of the chordate subphyla and has allowed us to resolve previous ambiguities about the orthology of many Wnt genes, including the identification of WntA for the first time in chordates. Moreover, we create the first complete expression atlas for the Wnt family during amphioxus development, providing a useful resource to investigate the evolution of Wnt expression throughout the radiation of chordates.

Conclusions: Our data underscore extraordinary genomic stasis in cephalochordates, which contrasts with the liberal and dynamic evolutionary patterns of gene loss and duplication in urochordate genomes. Our analysis has allowed us to infer ancestral Wnt functions shared among all chordates, several cases of function shuffling among Wnt paralogs, as well as unique expression domains for Wnt genes that likely reflect functional innovations in each chordate lineage. Finally, we propose a potential relationship between the evolution of WntA and the evolution of the mouth in chordates.
\end{abstract}

Keywords: Wht evolution, Genome stasis, Gene loss, Function shuffling, Chordate WntA, Ascidians, Vertebrates, Amphioxus

\section{Background}

The era of comparative genomics is providing a new perspective on the evolution of living diversity by revealing an unexpected and significant amount of genetic complexity that already existed in ancestral organisms. This new perspective implies that evolutionary simplification-and not only complexification resulting from the acquisition of gene novelties [1] or from the co-option of pre-existing or duplicated genes for novel functions [2-5]-has been a prominent trend across the Tree of Life (reviewed in [6]). At the genetic level, simplification has often been accompanied by pervasive gene loss, providing an important source of genetic variation, in many

\footnotetext{
*Correspondence: imls@st-andrews.ac.uk; canestro@ub.edu; ralbalat@ub.edu 'Biomedical Sciences Research Complex, School of Biology, University of St Andrews, North Haugh, St Andrews KY16 9ST, Scotland, UK

${ }^{3}$ Departament de Genètica, , Microbiologia i Estadística, and Institut de Recerca de la Biodiversitat (IRBio), Universitat de Barcelona, Barcelona, Spain Full list of author information is available at the end of the article
}

cases even eliciting major evolutionary adaptive responses-"the less is more" principle [7]-(reviewed in [8]). However, understanding the significance of gene loss [8] and function shuffling among duplicated genes [9] on the generation of biodiversity, and especially their impact on the evolution of the genetic mechanisms of development of complex multicellular animals, is still a fundamental problem in evolutionary and developmental biology. To explore this problem, we focus here on the evolution of the Wingless/Wnt family in chordates as a paradigm; the Wnt family is among the best characterized of all metazoan gene families (reviewed in $[8,10,11]$ ) and plays conserved roles in fundamental developmental processes in all animals, including determination of the primary body axis, spatial cell patterning, cell fate specification, and cell proliferation and migration (reviewed in [11-13]).

The Wnt family encodes a set of secreted glycoprotein ligands that trigger a variety of signal transduction

(c) The Author(s). 2018 Open Access This article is distributed under the terms of the Creative Commons Attribution 4.0 International License (http://creativecommons.org/licenses/by/4.0/), which permits unrestricted use, distribution, and reproduction in any medium, provided you give appropriate credit to the original author(s) and the source, provide a link to the Creative Commons license, and indicate if changes were made. The Creative Commons Public Domain Dedication waiver (http://creativecommons.org/publicdomain/zero/1.0/) applies to the data made available in this article, unless otherwise stated. 
pathways to regulate gene transcription in target cells (e.g., [14]). The transduction of Wnt signaling can occur via two main pathways, the "canonical" and the "noncanonical", although they are not mutually exclusive [11]. The "canonical" Wnt/ß-catenin pathway (a.k.a. cell-fate pathway) is mediated by the stabilization and transport of $\beta$-catenin into the nucleus, where it binds to transcription factors that regulate the expression of Wnt target genes, and thus specify cellular fates. The various Wnt signaling pathways that act independently of $\beta$-catenin have been described as non-canonical and, despite their diverse functions, they can be broadly grouped into the so-called "Wnt cell polarity" pathway [11]. The ascription of each Wnt family member to a particular pathway is not straightforward and it largely depends on the ability of each ligand to modulate $\beta$-catenin availability or, alternatively, to mediate cell behaviors. From cnidarians to vertebrates, for instance, Wnt1 and Wnt3 have been generally considered to signal through the canonical pathway, while Wnt5 and Wnt11 have been typically assigned to the Wnt cell polarity pathway [15-17]. The fact, however, that certain Wnt ligands can be promiscuous and activate more than one pathway (e.g., [18]) makes it difficult to assign them to any specific group.

Wnt genes are a metazoan novelty [1] found from sponges to humans that duplicated and diversified into 13 subfamilies-Wnt1 to Wnt11, Wnt16, and WntAbefore the bilaterian and cnidarian split $[19,20]$. Large-scale phylogenetic and genomic analyses have revealed that several Wnt genes have been lost and retained during animal evolution $[8,10,11,21-23]$. For instance, the gastropod Patella vulgata is the protostome that has suffered the greatest number of losses $(9$ out of 13, only preserving Wnt1, Wnt2, Wnt10, and WntA subfamilies), which is in stark contrast with the only two losses (Wnt3 and Wnt8) seen in another gastropod, Lottia gigantea [24, 25]. Other species such as Drosophila melanogaster and Caenorhabditis elegans, which have lost six (Wnt2 to 4, 11, 16, and A) and eight (Wnt1 to 3, 6 to 8, 11, and 16) subfamilies, respectively, make it evident that each animal lineage has shaped its own repertoire of $W n t$ genes. They also reveal that while many gene losses are recurrent and occurred independently in many lineages, others are ancestral and possibly important for the evolution of specific clades. For instance, the patchy pattern of absence/presence of Wnt9 suggests that it has been lost at least eight times during the evolution of arthropods, annelids, platyhelminthes, and cnidarians, while the absence of Wnt3 in all protostomes suggests an early loss of $\mathrm{Wnt} 3$ in the stem protostome ancestor, likely affecting the evolution of the entire group (reviewed in $[8,10,11]$ ).

In contrast to protostomes, vertebrates appear refractory to the loss of entire Wnt subfamilies. They have preserved at least one member in 12 out of the 13 subfamilies, with WntA the only subfamily that has not been found so far in vertebrates [24]. However, whether the tendency to retain Wnt subfamilies is specific to vertebrates or rather is a feature shared by all chordates (i.e., vertebrates + urochordates + cephalochordates) remains unkown. In urochordates (tunicates), the Wnt repertoire remains unresolved: phylogenetic classifications of Wnt genes from partial studies in three ascidians species (i.e., Halocynthia roretzi, Ciona robusta, and Botryllus schlosseri) have resulted in many unascribed Wnt genes (referred to as "orphan" Wht genes) and, in some cases, conflicting orthologies due to the high sequence divergence typical of these species [26-33]. In cephalochordates, so far only eight Wnt genes (Wnt1, 3, 4, 5, 6, 7, 8, 11) have been studied in one amphioxus species, Branchiostoma floridae [34-39] (reviewed in [40]), of which five (Wnt3, 5, 6, 7, and 8 ) have been partially characterized in another, B. lanceolatum $[41,42]$. Consequently, the taxonomic diversity of the analyzed urochordate and cephalochordate species has been too narrow, and the phylogenetic analysis of non-vertebrate chordate $W n t$ genes too ambiguous, to draw general conclusions about the evolution and function of orthologous Wnt subfamilies in the chordate phylum.

In order to provide a comprehensive view of the evolution of Wnt subfamilies in chordates, we have conducted an exhaustive survey of Wht genes in genomic databases of ten ascidian (urochordate subphylum) and three amphioxus (cephalochordate subphylum) species and have generated the first complete atlas of developmental expression of the Wnt family in amphioxus. Our phylogenetic analysis represents, to our knowledge, the first fully resolved reconstruction of all Wnt subfamilies in the three chordate subphyla, resolving previous ambiguous or conflictive ascriptions of orthology. Our study reveals opposite trends in Wnt gene losses and retentions in cephalochordates and urochordates: while amphioxus shows a conservative pattern of evolution, retaining the complete ancestral repertoire of chordate Wnt subfamilies, ascidians in contrast reveal a dynamic pattern of evolution, with numerous gene losses and duplications. Our study also demonstrates for the first time the presence of WntA genes in chordates (both in cephalochordates and in urochordates), which implies that the absence of the WntA subfamily in vertebrates is not due to an ancestral loss in chordates as previously suggested, but to a specific gene loss occurring during the early evolution of vertebrates. Finally, our detailed atlas of Wnt expression in amphioxus, including the newly identified $W n t A$ genes in non-vertebrate chordates as well as several cases of "function shuffling" [9], allows us to evaluate the contributions of different Wnt subfamilies to the diversification of each chordate subphylum. 


\section{Results}

\section{The Wnt gene repertoire in non-vertebrate chordates}

Our comprehensive survey of Wnt genes in genomic databases of 13 non-vertebrate chordate species-three cephalochordate species and ten urochordate species representing five ascidian families from two different orders (two solitary Cionidae and two solitary Ascidiidae within Phlebobranchia; and two solitary Pyuridae, three solitary Molgulidae, and one colonial Styelidae within Stolidobranchia)-identified 156 Wnt genes (Additional file 1: Table S1), which constitutes the first comprehensive catalog of Wnt genes in non-vertebrate chordates. Our phylogenetic analyses, which included a total of 247 Wnt sequences from 19 species (sequence alignment in Additional file 2) representing all major metazoan groups, from cnidarians to vertebrates, sorted the non-vertebrate chordate Wnt sequences into 13 monophyletic groups corresponding to the 13 known Wnt subfamilies (Fig. 1).

\section{Conservative Wnt evolution in cephalochordates}

Our phylogenetic analyses revealed that the three Branchiostoma species possess one ortholog for each of the 13 ancient Wnt subfamilies (Fig. 1a, b; see Additional file 2 for sequence alignment). Our results identified five $W n t$ genes that had not been analyzed in cephalochordates before and corroborated the orthology of eight previously described amphioxus Wnt genes [34-39, 41] (reviewed in [40]). We further extended our Wnt survey to the transcriptome project of Asymmetron lucayanum, a cephalochordate distantly related to the other Branchiostoma species [43]. We identified $13 \mathrm{Wnt}$ sequences, mostly full length (Additional file 1: Table S1), each one orthologous to one of the $13 \mathrm{Wnt}$ subfamilies (Additional file 1: Figure S4; see Additional file 3 for sequence alignment). The fact that all amphioxus Wnt orthologs form a single cluster nested within vertebrate and ambulacrarian sequences from each Wnt subfamily suggests that neither gene duplications nor gene losses affected the evolution of Wnt subfamilies in the cephalochordate subphylum. Our findings, therefore, reinforce the idea of genomic and morphological evolutionary stasis attributed to cephalochordate species [41, 44-48] (reviewed in [49]), in spite of divergence times estimated at over tens of millions of years ago [43, 50-53].

\section{Liberal Wnt evolution with losses and duplications in ascidian urochordates}

Our phylogenetic analyses provided the first fully resolved orthology of ascidian Wnt genes, allowing us to rename previously described genes still classified as "orphan Wnts" with unclear orthology, as well as to settle conflicting orthology assignments, probably caused by limited species sampling [29-32] (Fig. 1a and Additional file 1: Table S1). The phylogenetic tree showed long branches for ascidian Wnt genes, which rarely clustered as the sister group of vertebrate Wnt genes within each Wnt subfamily, as would be expected from their taxonomic relationships, likely due to artifactual "long-branch attraction" [54]. Our results showed that ascidians, in contrast to amphioxus, do not conserve the entire Wnt repertoire and have suffered various events of gene loss, as well as gene duplications (Fig. 1). While some of the losses appeared to be ancestral, resulting in the absence of Wnt subfamilies in all ascidian species, other losses and duplications affected different families and orders heterogeneously, suggesting a more dynamic evolution of Wnt genes in ascidians than in the conservative amphioxus. Wnt4 and $W n t 8$, for instance, are absent in all analyzed species, plausibly due to two ancestral gene losses that occurred prior to the ascidian radiation, and therefore relevant to our understanding of the divergence in developmental mechanisms between ascidians and other chordates (Fig. 1b). On the other hand, Wnt1 and Wnt11 appear to be absent in species of the Phelobobranchia suborder and Molgula genus, respectively, while Wnt3 is only absent in B. schlosseri. It seems, therefore, that loss of Wnt genes might have contributed to the genetic divergence between different groups or even single species of ascidians.

Our results, moreover, revealed that the Wnt5 subfamily in the Stolidobranchia order had experienced extensive amplification by gene duplication, affecting all six analyzed species (Fig. 1b). The fact that many of these Wnt5 duplicates appeared to be located in the same genomic regions suggested that they originated by tandem gene duplications (Additional file 1: Figure S1). The complex phylogenetic reconstructions of the ascidian Wnt5 clade were difficult to interpret, suggesting either the occurrence of independent gene duplications in different lineages after events of speciation or, alternatively, ancestral Wnt5 duplications in stem Stolidobranchia, followed by multiple gene losses and events of gene conversion (Additional file 1: Figure S1). In either case, the expansion of Wnt5 in Stolidobranchia provides a singular case of Wnt subfamily amplification in non-vertebrate chordates, suggesting that the evolution of this order of ascidian species has been accompanied by a relaxation of the evolutionary constraints that maintain Wnt5 genes as a single copy gene in other species. This may be linked to the recruitment of new Wnt5 paralogs in biological innovations unique to this group of ascidians.

Overall, the dynamic pattern of gene losses and duplications of Wnt genes observed among different orders, families, or individual species of ascidians correlates with the burst of morphological diversification within the urochordate subphylum, contrasting with the conservative pattern of Wnt evolution and morphological stasis observed in cephalochordates. 

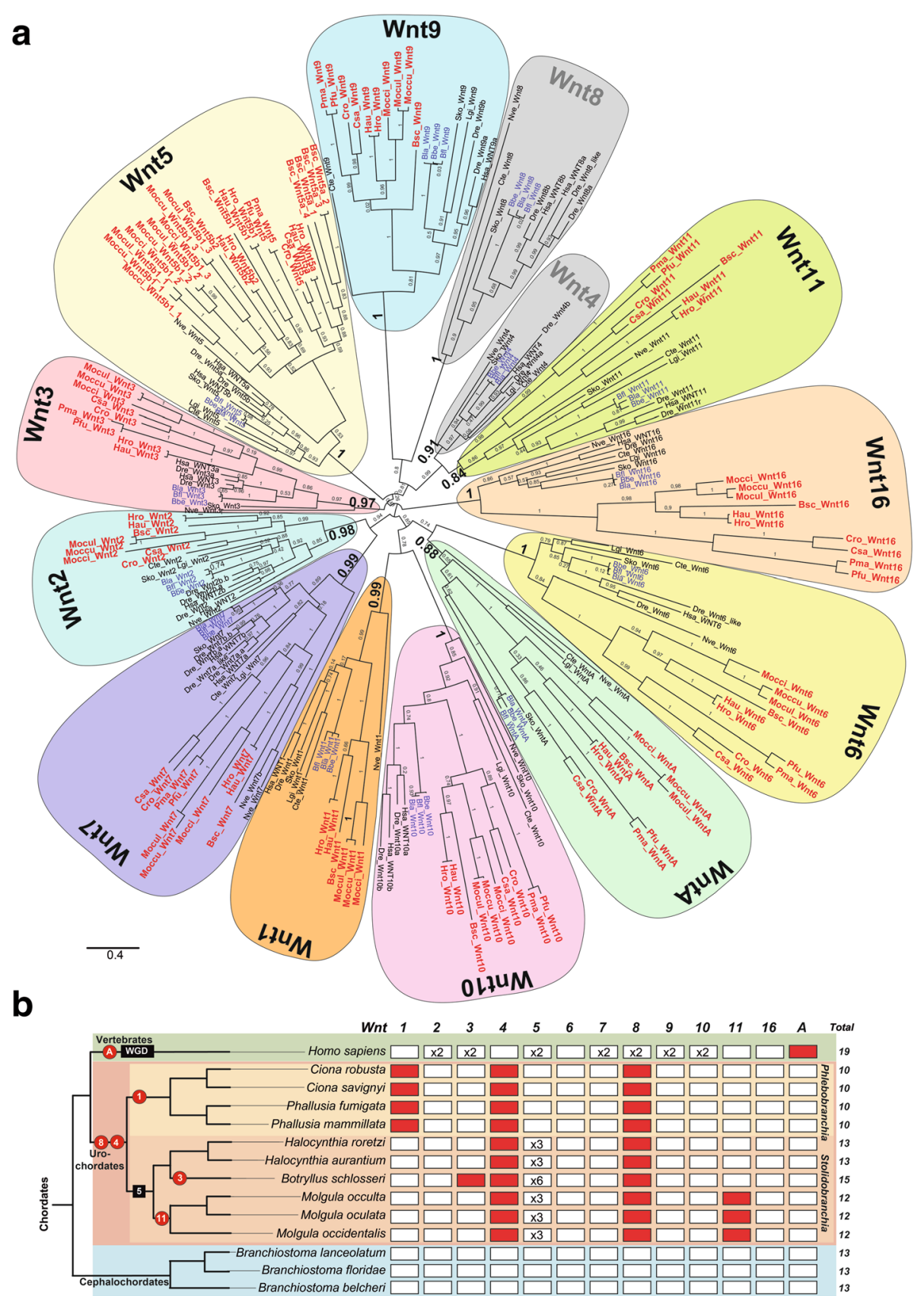

Fig. 1 (See legend on next page.) 


\begin{abstract}
(See figure on previous page.)
Fig. 1 Wnt family evolution in chordates. a The ML phylogenetic tree reveals a conservative pattern of genomic evolution in cephalochordates (species names in blue), which preserve all 13 Wnt subfamilies, contrasting with the dynamic pattern of genomic evolution in urochordates (in red), which are characterized by several gene losses and duplications. The scale bar indicates amino acid substitutions. Values for the approximate likelihood ratio test (aLRT) are shown at nodes. Species are as follows. Chordate species: Urochordates: Botryllus schlosseri (Bsc), Ciona savignyi (Csa), Ciona robusta (Cro; formerly Ciona intestinallis), Halocynthia roretzi (Hro), Halocynthia aurantium (Hau), Mogula occulta (Moccu), Mogula oculata (Mocul), Mogula occidentalis (Mocci), Phallusia fumigata (Pfu), and Phallusia mammillata (Pma). Cephalochordates: Branchiostoma belcheri (Bbe), Branchiostoma floridae (Bf), Branchiostoma lanceolatum (Bla). Vertebrates: Danio rerio (Dre), Homo sapiens (Hsa). Non-chordates species: hemichordate Saccoglossus kowalevskii (Sko), annelid Capitella teleta (Cte), mollusk Lottia gigantea (Lgi), and cnidarian Nematostella vectensis (Nve). b The Wnt gene catalog (Wnt1-11, Wnt16 and WntA) present (white squares) or absent (red squares) in the three chordate subphyla, allowing inference of plausible events of gene losses (red circles; the number or letter inside the circle indicates the lost Wnt subfamily) and duplications (black squares; the number inside the square indicates the duplicated subfamily) during the evolution of different lineages. While some losses appear to be ancestral (e.g., Wnt8 and Wnt4 losses in stem urochordates), others only affected specific groups or species (e.g., Wnt1 loss in Phlebobranchia, Wnt11 in Molgulas, and Wnt3 in Botryllus). In vertebrates, Wnt subfamilies expanded following the rounds of whole-genome duplications (WGD) that occurred during their early evolution [4], while in the rest of chordates all Wnt are conserved as a single copy, with the exception of Wnt5 in Stolidobranchian ascidians, which has suffered multiple events of tandem gene duplications (see Additional file 1: Figure S1)
\end{abstract}

\section{WntA, lost and found in chordates}

Our analysis also led to the identification of $W n t A$ genes in cephalochordates and urochordates (Fig. 1 and Additional file 1: Table S1). This finding was of special interest since WntA had previously been identified in cnidarians, protostomes, and ambulacrarian deuterostomes (e.g., in the hemichordate Saccoglossus kowalevskii and the echinoderm Strongylocentrotus purpuratus), but not in any chordate, leading to the suggestion that the WntA subfamily had been lost in stem chordates [10, 24]. The identification in this study of WntA genes in both cephalochordate and urochordate species implies, therefore, that $W n t A$ was present in the last common chordate ancestor, preserved in cephalochodates and urochordates, but specifically lost during the early evolution of the vertebrate lineage.

\section{The complete expression atlas of cephalochordate Wnt genes}

The apparent conservative evolutionary stasis shown in amphioxus and the finding that amphioxus possesses a full and non-redundant Wnt repertoire make this organism a very attractive model to infer the roles of Wnt genes in the ancestral stem chordate, and from comparative studies, to analyze the impact of changes in the Wnt repertoire during the evolution of each chordate subphylum. In order to obtain the first comprehensive stage-matched developmental expression atlas for the cephalochordate Wnt repertoire, we performed whole-mount in situ hybridization (WMISH) for all Wnt genes in the European species B. lanceolatum (Figs. 2 and 3). Our results revealed that Wnt genes were expressed in a robust and precise tissue-specific fashion, with significant overlap among several amphioxus Wnt paralogs. Nevertheless, we also saw a number of differences in the expression of different paralogs, suggesting a choreographed modulation of their expression domains throughout development to generate spatio-temporally complementary patterns (a gene-by-gene detailed description of the expression patterns of all Wht genes shown in Fig. 2 is provided in
Additional file 1: Text S1 and summarized in Fig. 4). Overall, Wnt expression appears to be highly dynamic, spanning a broad variety of tissues derived from all three germ layers, which precisely up- or down-regulate different Wnt paralogs throughout development.

\section{Posterior dominance of Wnt expression}

"Posteriority" is likely the most conspicuous hallmark observed in the expression domains of the majority of amphioxus Wnt genes. At the blastula stage, Wnt1, $W n t 8$, and $W n t 11$, which were the first Wnt genes to be expressed in amphioxus (class A genes in Fig. 2), showed an evident restriction of their expression domains to the posterior half of the embryo. Thus, while Wnt1 expression clearly labeled the vegetal pole, Wnt8 and Wnt11 were expressed at the equator of the prospective posterior pole [55]. At the gastrula stage G3, along with the early class A genes, Wnt3, Wnt4, and Wnt5 expression domains appeared surrounding the blastopore (white asterisks, class B genes in Fig. 2), as well as Wnt6 a little later (at stage G7). They were expressed in these posterior regions through neurulation (N2 and N3) until larval stages (L1). Close observation of the blastoporal view revealed some degree of overlap among gene expression patterns, but also important differences among the Wnt expression domains of each paralog. For instance, while Wnt1 signal labeled the entire circumference surrounding the blastopore (Fig. 2, G3 column), Wnt3 demarcated a narrower outer ectodermal strip of cells into G7 (Fig. 2). Wnt8 and Wnt11 signals were excluded from the edges of the blastopore and reached more central endomesodermal regions (Fig. 2). At G3, Wnt4 signal was also strongly visible in the endomesoderm near the blastopore, but rather than being restricted to the posterior region, it spanned the entire layer surrounding the gastrocoel and was excluded entirely from the ectoderm (Fig. 2). Finally, Wnt5 most strongly marked the endomesoderm of the dorsal blastopore lip (Fig. 2). Most of these early posterior Wnt expression domains were 


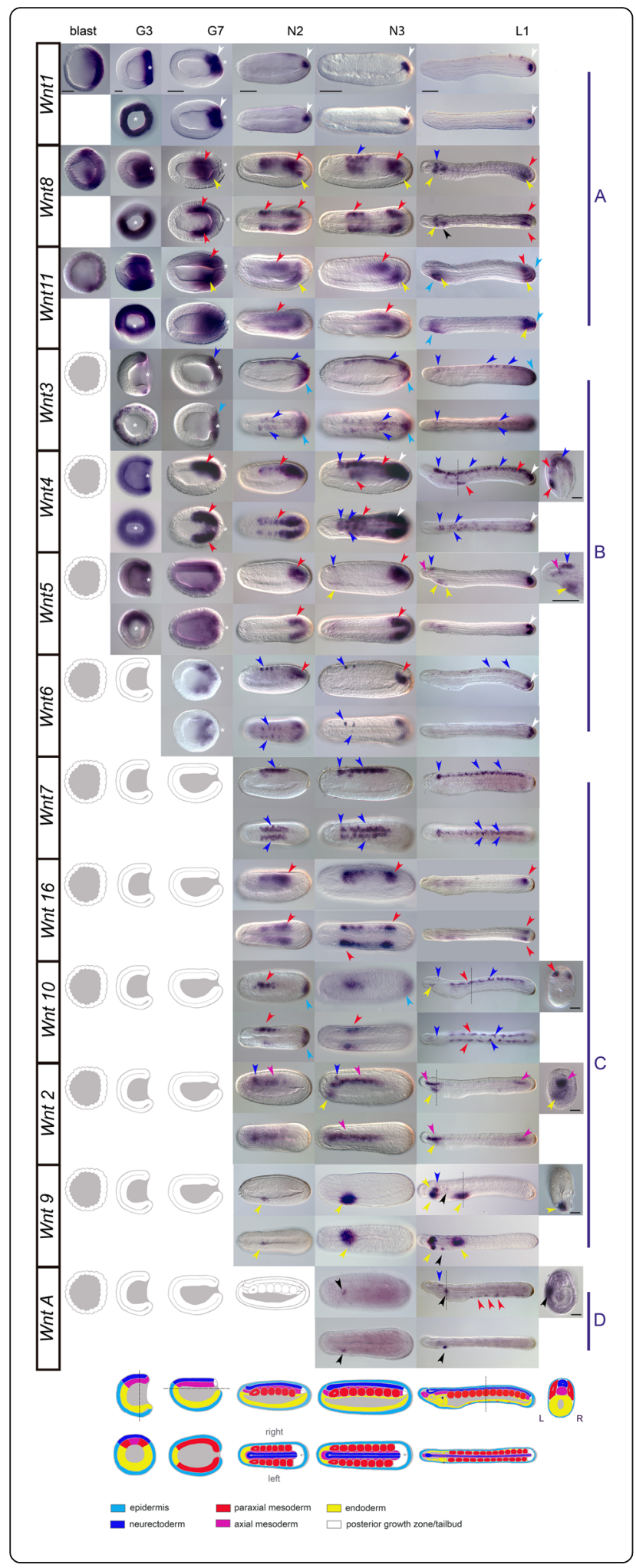

Fig. 2 Complete atlas of Wnt expression in the cephalochordate Branchiostoma lanceolatum. Stage-matched expression patterns of 13 amphioxus Wnt genes reveal complex spatio-temporal choreography throughout embryogenesis. Wht genes are ordered according to their developmental timing of expression: Wnt 1 , Wnt8, and Wnt11 are first expressed in the blastula (class A genes); Wnt3, Wnt4, Wnt5, and Wnt6 begin in the gastrula (class B genes); Wnt7, Wnt16, Wnt10, Wnt2, and Wnt9 in the early neurula (N2; class C genes); and WntA in the mid-late neurula (N3 class D gene). All Wnt genes are expressed through to early larval stages (L1), prior to mouth opening. Arrowheads are color-coded to match schematics based on germ layer origins: light blue, ectoderm including tail fin (fi); dark blue, neural tube ( $n t)$ and cerebral vesicle (cv); yellow, endoderm derivatives including foregut (fg), hindgut ( $h g)$, preoral pit (pp), endostyle (es), club-shaped gland (csg), and gill slit primordium (gs); orange, mesendoderm; red, mesoderm derivatives including somites (so) and mesothelial cells (me); fuchsia, axial mesoderm derivatives including notochord (no); white, tailbud structures (tb, boxed), including neurenteric canal and chordoneural hinge; black, mouth primordium (mo). Note that only some somites are represented for the sake of clarity to permit visualization of underlying tissues. For all genes, anterior is to the left and dorsal up; developmental stages are indicated at the top and embryo schematics are shown at the bottom. Lateral and dorsal views are shown, with the exception of blastulae (blast), for which only lateral views are represented, and gastrula stage G3, for which lateral and blastopore (white asterisk) views are shown. Dotted lines indicate planes of sectioning in larvae L1. Scale bars $=50 \mu \mathrm{m}$. Please see Additional file 1: Text S1 for a detailed gene-by-gene description of all amphioxus Wnt expression patterns

steadily maintained throughout development. The Wnt1 expression domain, for instance, remained in the posterior wall of the neurenteric canal after elongation and closure of the blastopore until at least the early larval stage (Fig. 2, L1 column). Wnt5 strongly marked the posterior growth zone during neurulation (Fig. 2, N2 and N3 columns), culminating in strong tailbud expression in larvae (Fig. 2, L1 column). Wnt3 signal was observed up to L1 stage in the posterior-most ectoderm fated to become tailfin, abutting the Wnt1 domain.

Posteriority was also observed for some Wht genes with late expression onset (class $\mathrm{C}$ genes in Fig. 2). Of these, Wnt10, for instance, showed a new ectodermal expression domain in the most posterior part of the embryo at N2 and N3 (Fig. 2), which subsequently faded concomitantly with the appearance of Wnt11 expression in this same region. This Wnt11 expression clearly marked the entire fin in the one-gill-slit larval stage (Fig. 2, L1 column, and Fig. 3b). In summary, our data show that nine out of the $13 \mathrm{Wnt}$ amphioxus Wnt genes showed posterior expression domains (Fig. 4), highlighting posteriority as one of the main hallmarks of this gene family.

\section{Mesodermal Wnt expression and somite formation}

In addition to the propensity for posterior dominance, another important source of Wnt signaling was observed in the presomitic and axial mesoderm, where seven out of the 13 Wnt paralogs were expressed. Besides the aforementioned early overlapping expression domains of 
a

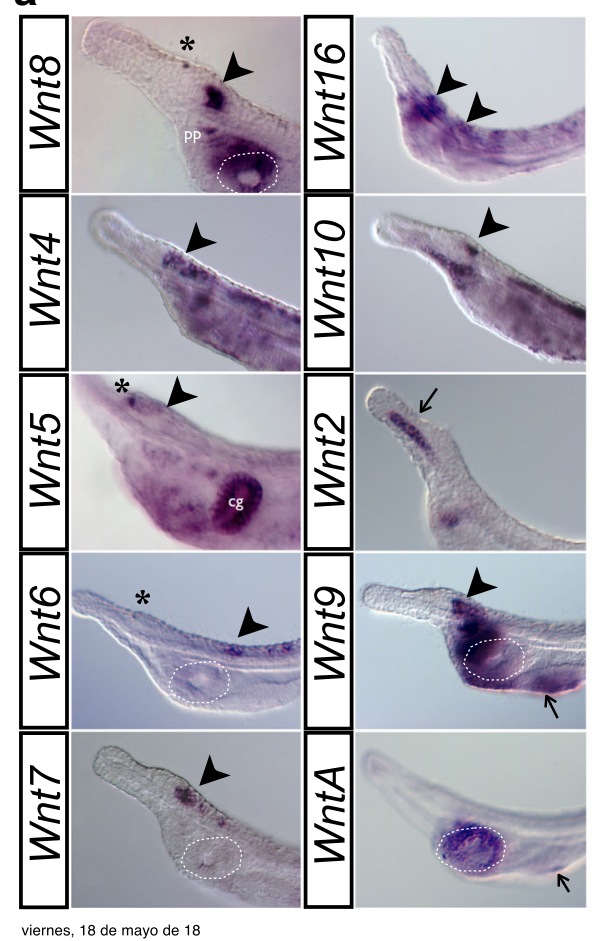

b

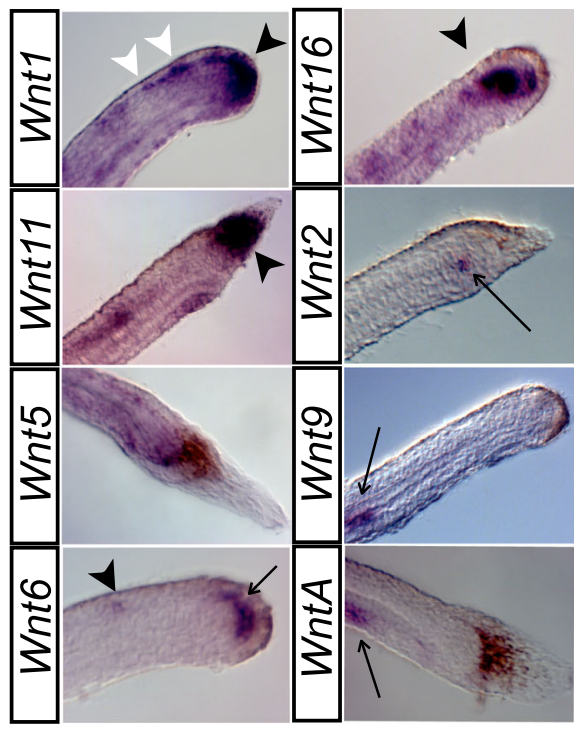

Fig. 3 Wnt expression in one-gill-slit amphioxus larvae. a Anterior expression domains of selected Wnt genes ordered as in Fig. 2: Wnt8, posterior cerebral vesicle (black arrowhead), preoral pit ( $p p)$, endostyle, and around the mouth; Wnt4, posterior cerebral vesicle (black arrowhead) and neural tube; Wnt5, cerebral vesicle (black arrowhead), club-shaped gland (cg), and weakly in anterior notochord; Wnt6, isolated spots in neural tube (black arrowhead); Wnt7, posterior cerebral vesicle (black arrowhead); Wnt16, neural tube, including the hindbrain (black arrowheads); Wnt10, posterior cerebral vesicle (black arrowhead); Wnt2, anterior notochord (black arrow), and isolated cells of the anterior endoderm; Wnt9, posterior cerebral vesicle (black arrowhead), pharyngeal endoderm around the preoral pit, endostyle, and the first gill slit primordium (black arrow); WntA, around the mouth and in the first forming gill slit (black arrow) and within the rostral coelom and muscle. Black asterisk indicates pigment spot in the forming frontal eye; white dotted line indicates mouth. $\mathbf{b}$ Posterior expression domains. Wnt1, posterior neural tube (white arrowheads) and neurenteric canal hinge (black arrowhead); Wnt11, tail fin (black arrowhead); Wnt5, tailbud region; Wnt6, neural tube (black arrow) and posterior wall of the neurenteric canal (black arrowhead); Wnt16, posterior wall of the neurenteric canal and posterior mesoderm of the last somites (black arrowhead); Wnt2, posterior notochord (black arrowhead); Wnt9, midgut endoderm (black arrowhead); WntA, mesothelial cells (black arrowhead). Older larvae have tail fins containing brown pigment. All views are lateral, with anterior to the left and posterior to the right

Wnt8 and Wnt11 observed in the posterior endomesoderm surrounding the blastopore at G3, new expression domains of Wnt4, Wnt5, Wnt6, and Wnt16 consecutively appeared in the most posterior mesoderm by G7, $\mathrm{N} 2$, N3, and L1, respectively, in a temporally orchestrated manner. At the one-gill-slit larval stage, $W n t 5$ and Wnt16 expression was maintained in the posterior-most mesoderm (Fig. 2, L1 column, and Fig. 3b). In addition to the Wnt-positive posterior mesodermal domain, several other Wnt expression domains could be identified in temporally dynamic complementary (as well as overlapping) patterns, in some cases forming nested domains along the anteroposterior axis (for instance, Wnt8/16Wnt11-Wnt8/16-Wnt4/5/6). In other cases Wnt expression domains differed in their dorso-ventral extent within somites. For instance, Wnt10 appeared excluded from dorsal domains compared with Wnt16 in the N2 stage. Wnt16 signal was observed in the last pair of formed somites by L1, while Wnt10 appeared to be dorsally restricted in all mature somites (see cross-section in Fig. 2) and excluded from this last pair. No Wnt signal was observed in the anteriormost pair of somites at any stage of development.

In contrast to the paraxial mesoderm, surprisingly few Wnt genes appeared to be expressed in chordamesoderm or other mesoderm derivatives. For example, only Wnt2 and $W n t 5$ were expressed in the notochord. Wnt2 signal was localized to the anterior two-thirds of the chordamesoderm during neurula stages (Fig. 2), becoming restricted to the most caudal and rostral portions in one-gill-slit larvae (Fig. 3); in contrast, Wnt5 was conspicuously expressed in the anterior notochord only in larval stages (Fig. 2, L1 column, and Fig. 3). Finally, several non-myotomal structures of mesodermal origin appeared to express Wnt genes in restricted domains. Wnt4 signal was observed in mesothelial cells in late 


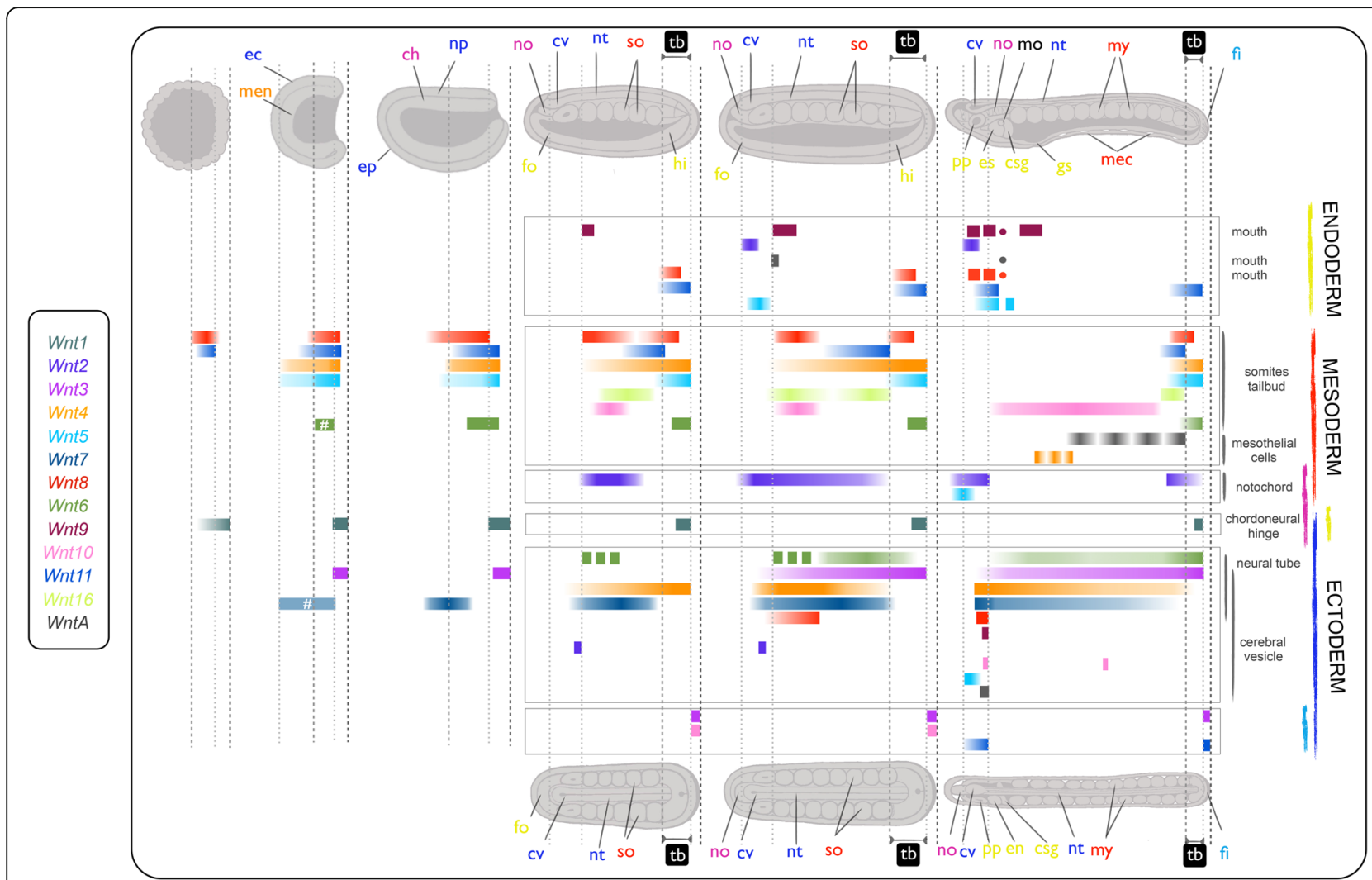

Fig. 4 Wht expression in B. lanceolatum is complex and spatio-temporally dynamic. Color-coded horizontal bars represent the expression domains of Wht genes (see left box) and refer to schematic illustrations of B. lanceolatum embryos from blastula to early larva (lateral view at the top and dorsal view at the bottom; anterior is to the left and posterior to the right; main structures are labeled), organized by germ layer into endoderm (yellow), mesoderm (red), chordamesoderm (magenta), and ectoderm (dark blue, neural derivatives; light blue, epidermal derivatives). Vertical dotted lines delimit antero-posterior reference domains and underscore hypothesized Wnt functions during neural regionalization, posterior growth, and structure differentiation. The hash sign denotes minor differences with B. floridae expression. Abbreviations: ec ectoderm, men mesendoderm, ep epidermis, ch chordal plate, $n p$ neural plate, no notochord, $c v$ cerebral vesicle, fo foregut, $n t$ neural tube, so somites, hi hindgut, tb tailbud, pp. preoral pit, es endostyle, csg club-shaped gland, gs gill slit primordium, my myomere, mec mesothelial cells, fi fin, mo mouth primordium. See text for further details

neurula and early larval stages on the left side adjacent to the pharynx (Fig. 2). WntA was expressed in larval stages in mesothelial cells between the ventral endoderm of the gut and the ectoderm in both early and late larvae (Figs. 2, 3b, and 4).

\section{Endodermal Wnt expression}

In addition to mesodermal expression, Wnt signal was also evident in endodermal derivatives. By the gastrula stage, Wnt8 and Wnt11 expression domains were already observed in the endodermal portion delimiting the blastopore, expression domains that persisted until N3 and L1, respectively (Fig. 2). Many of the Wnt genes expressed in the posterior growth zone or tailbud also labeled hindgut domains in that area (e.g., Wnt4; Fig. 2). During larval stages, new anterior Wnt expression domains became evident in the anterior region and other parts of the digestive system (Fig. 2, L1 column). Some, such as Wnt5, Wnt2, and Wnt9, appeared to be already expressed at late neurula stages in anterior endoderm
(Fig. 2, N2 and N3 columns). Wnt genes labeling specific derivatives by $\mathrm{L} 1$ included $W n t 8, W n t 9$, and $W n t A$ in the mouth primordium, Wnt2, Wnt5, Wnt8, and Wnt11 in Haetschek's diverticula, Wnt8 and Wnt9 in the endostyle, and Wnt9 in the branchial primordium (Fig. 2, L1 column). Once the mouth was open and the first gill slit was clearly formed, Wnt5 labeled the club-shaped gland, while $W n t 8$ and $W n t 9$ labeled the preoral pit, WntA the entire circumference of the mouth, and Wnt9 and WntA the first gill slit (Figs. 2 and 3a). Wnt4 and Wnt2 signal appeared in a few cells of the endostyle along with Wnt8 and Wnt9. Wnt10 signal was also clearly evident in cells lining the rostral coelom (Fig. 3a). Posteriorly, Wnt6 appeared to be expressed in a single line of cells demarcating the posterior wall of the neurenteric canal, and Wnt9 labeled cells within the posterior gut (Fig. 3b).

\section{Ectodermal Wnt expression}

Ectodermal Wnt expression was detected in the epidermis as well as the nervous system. Besides the sequential 
coexpression of Wnt3, Wnt10, and Wnt11 in the tip of the tail, the ventral epidermis of the anteroventral region at the level of the Haetschek's diverticulum also appeared to express Wnt11 and Wnt5 in L1 larvae (Fig. 2, L1 column). At some stage, all Wnt genes-with the exception of Wnt11-labeled the developing central nervous system (CNS), consisting of cerebral vesicle and nerve cord (Figs. 3 and 4). Thus, the invaginating neural tube expressed Wnt7, Wnt3, Wnt6, Wnt2, Wnt4, and Wnt8 starting in neurula stages, while Wnt5, Wnt10, and WntA signal appeared later in early larvae (Fig. 2). The spatio-temporal expression profiles differed among ligands, ranging from continuous Wnt7 expression throughout the majority of the nervous system until larval stages, to the more restricted patterns shown by Wnt2, Wnt4, Wnt6, WntA, Wnt10, or Wnt5. Some, such as WntA or Wnt10, only labeled a few isolated cells within the cerebral vesicle in the early larval stage L1 (Fig. 2, L1 column). However, by the one-gill-slit larval stage, regionalisation of the cerebral vesicle became apparent, with Wnt5 expression restricted to an anterior domain encompassing the frontal eye (Fig. 3a), while genes such as Wnt4, Wnt7, Wnt8, Wnt9, and Wnt10 (and possibly Wnt16) marked posterior regions of the cerebral vesicle or the hindbrain (Fig. 3b).

\section{WntA expression in non-vertebrate chordates}

We paid special attention to further investigating the function and evolution of our newly discovered chordate $W n t A$ genes. We therefore analyzed the expression patterns of WntA during embryonic development not only in the amphioxus B. lanceolatum but also in two additional chordate species, the ascidians $C$. robusta (Phelobobranchia order) and $H$. roretzi (Stolidobranchia order). WntA expression, however, was not detected during embryonic development in either of these two ascidian species (Additional file 1: Figure S2). This lack of expression of WntA was consistent with the absence of ESTs from embryonic libraries in databases of C. robusta and $H$. roretzi; the only existing ESTs of the WntA gene (FF969784 and FF969783 of C. robusta) came from adult animals. These results suggested, therefore, that WntA might be exclusively expressed at postembryonic stages or during adulthood in ascidians.

In contrast to ascidians, we found that WntA was expressed in a complex pattern during amphioxus embryonic development. Our results revealed that amphioxus WntA was the last Wnt gene to turn on in mid-late neurulae, with expression in only one or two cells located anteriorly on the left side under the ectoderm (Fig. 2), likely in the oral mesovesicle (OMV). The OMV is a coelomic vesicle that develops from the posterior ventral corner of the left first somite, and which has been associated with amphioxus mouth opening [56]. This expression domain persisted throughout development, accompanied by punctuated expression in the posterior cerebral vesicle from the late neurula until the pre-mouth larval stage (see above). WntA signal was also observed in cells between the ectoderm and endoderm of the forming gut of early and one-slit larvae (Fig. 2, cross-section, and Fig. 3), possibly in the mesothelial precursors of the "amoebocytes", considered to be the homologs of the vertebrate blood cells [57]. Strong expression was further evident all around the mouth opening in these late larvae (Fig. 3a). This gene therefore represents a late-phase Wnt (class D) that plays a major post-neurulation role in differentiating structures such as the mouth and cerebral vesicle, and possibly in the circulatory system of amphioxus.

\section{Discussion}

\section{Evolutionary patterns of Wnt subfamilies in non-} vertebrate chordates

The identification and fully resolved phylogenetic reconstruction of the entire Wnt repertoire in several species of urochordate and cephalochordate (Fig. 1 and Additional file 1: Figure S4) permit the first complete reconstruction of the evolution of the Wnt subfamilies in chordates, revealing that each subphylum follows different evolutionary trajectories. Cephalochordates show a conservative evolutionary pattern, without either apparent gene duplications or gene losses since the cephalochordate lineage diverged from other chordates more than half a billion years ago $[43,50]$. This finding suggests that the amphioxus genome has preserved the complete and prototypical chordate/deuterostome/eumetazoan Wnt repertoire (Fig. 1b). Analyses of many amphioxus gene families (e.g., Hox cluster [58], homeobox gene families [59], gene families of the steroid and retinoic acid signaling pathway [60-62], the tyrosine kinase superfamily [63], DNA-methylation genes [64, 65], and the FGF gene family [66]) reinforces the idea of evolutionary stasis of cephalochordate genomes [43, 44, 48]. The expression patterns of all $W n t$ genes analyzed here in B. lanceolatum are congruent with the expression of their eight orthologs previously characterized in the American lancelet species B. floridae [34-39] (Wnt1, 3, 4, 5, 6, 7, 8, and 11; reviewed in [40]), which extends previous reports of cephalochordate stasis of morphology and developmental expression patterns [41, 46, 47, 67] and provides further support to the idea that the ancestral chordate resembled in many respects a modern amphioxus $[58,59]$.

In sharp contrast to the conservative nature of the amphioxus Wnt complement, ascidians show a dynamic pattern of evolution, including several gene losses and duplications (Fig. 1b). Some of the gene losses are likely ancestral, affecting the early stem of the ascidian lineage, since some paralogs are absent in all ascidian species. In contrast, other losses appear to be more recent, affecting 
only some groups of ascidians (i.e., Wnt1 in the Phelobobranchia suborder and Wnt11 in the Molgula genus), or limited to specific species (Wnt3 to B. schlosseri). Inferring the point at which Wnt losses occurred is not only important to better understand their possible impact on the divergence of developmental mechanisms between ascidians and other chordates, but will also help elucidate how they may have contributed to genetic and morphological divergence during the ascidian radiation. Moreover, the extensive gene duplications of the Wnt5 subfamily of the Stolidobranchia order may have also facilitated divergence within this order. Since this is the only case of amplification of all Wnt subfamilies analyzed in non-vertebrate chordates, and recurrent tandem duplications have independently affected several species of the Stolidobranchia, the developmental constraints to maintain Wnt5 as single copy seem to have been exclusively relaxed in this order of ascidians.

In contrast to cephalochordates and urochordates, many vertebrate Wnt subfamilies consist of two ohnologues (e.g., human Wnt subfamilies 2, 3, 5, 7, 8, 9, and 10), which originated during the two rounds of whole-genome duplications (2R-WGD) that occurred during early vertebrate evolution [4]. The differences in the retention rate of Wnt paralogs between vertebrate and non-vertebrate chordates are possibly due to the different modes of duplication, i.e., genome duplication vs small-scale duplication (reviewed in $[4,8]$ ), and suggest that duplication within Wnt subfamilies in non-vertebrate chordates might be impaired by dosage imbalance with the exception of the Wnt5 subfamily in the Stolidobranchia order. Remarkably, WntA is the only Wnt subfamily absent in vertebrates. To investigate when the WntA gene was lost, we analyzed the Wnt catalog of two additional vertebrate species: the lamprey Petromyzon marinus, an agnathan representative, and the shark Callorhinchus milii, a cartilaginous fish. We identified 24 Wnt sequences in $P$. marinus and 20 in C. milii databases (Additional file 1: Table S1). In our phylogenetic reconstruction, $P$. marinus and $C$. milii sequences distributed among all Wnt subfamilies, with the exception of the WntA subfamily (Additional file 1: Figure S4; see Additional file 3 for sequence alignment), suggesting that $W n t A$ was lost early in vertebrate evolution, before the divergence of jawless and gnathostome lineages. It can be argued, therefore, that WntA plausibly became dispensable in the primitive vertebrate either because alternative pathways or genes compensated for its function, or because environmental or physiological changes made them dispensable [8]. Finally, taking advantage of genomic information on the new Wnt genes identified in this study, we have re-evaluated the conserved synteny of previously postulated Wnt clusters [25]. Amphioxus has four clusters: the Wnt9-Wnt1-Wnt6 cluster, the Wnt2-Wnt16 cluster, the Wnt3-Wnt10 cluster, and the
Wnt5-Wnt7 cluster (Fig. 5; Additional file 1: Table S3). In ascidians, we have found evidence for a single cluster: Wnt9-Wnt6-Wnt3 in C. robusta and Wnt6-Wnt3 in C. savignyi (Fig. 5; Additional file 1: Table S3). Lamprey conserves at least five clusters: the Wnt9-Wnt1-Wnt6 cluster, the Wnt3-Wnt10 and at least three $W n t 5-W n t 7$ clusters (Fig. 5; Additional file 1: Table S3). Interestingly, cluster conservation is higher between lamprey and amphioxus than between either of these and human (Wnt5-Wnt7, and $W n t 5-W n t 7$ and $W n t 2-W n t 16$, respectively), pointing to genomic rearrangements in the lineage leading to humans. In summary, our work highlights how distinct genomic rearrangements and patterns of gene conservation, loss, and duplication shaped differently the Wnt repertoire in amphioxus, ascidians, and vertebrates, and provides an evolutionary scenario that will facilitate future investigations of how these changes relate to adaptations to the environmental and physiological requirements evolved by each subphylum.

\section{Comparative analysis of Wnt expression patterns during embryonic development in the three chordate subphyla} Our assignment of all non-vertebrate chordate Wnt genes to the different Wnt subfamilies permits the first comparison of expression patterns of all orthologs among vertebrate and non-vertebrate chordates. With the complete cephalochordate dataset in hand, we were able to compare the expression patterns of all B. lanceolatum Wnt genes with the reported patterns of vertebrate Wnt genes and those available for ascidians (Additional file 1: Figure S3 and Text S2). Overall, our analysis revealed three main situations: first, cases of orthologous Wnt genes that share expression domains in homologous structures among chordate species, likely reflecting ancestral functional conservation; second, homologous structures that share Wnt expression domains, although the orthology of the ligands is not conserved among taxa, suggesting, therefore, gene function shuffling; and third, Wnt expression domains absent in amphioxus but present in other chordates, possibly reflecting lineage-specific Wnt innovations during the evolution of Olfactores (vertebrates + urochordates), or simplifications of the cephalochordate lineage.

\section{Ancestral conserved Wnt functions in chordates}

Amphioxus Wnt7 is highly expressed in the CNS (Fig. 2), a feature that is shared with ascidian and vertebrate Wnt homologs [27, 34] (reviewed in Additional file 1: Figure S3 and Text S2). The posterior expression of Wnt5 in somite and muscle development is also conserved in amphioxus (Fig. 2) ([39] and this work), vertebrates [68], and ascidians $[28,69]$. Wnt9 expression is conserved in endodermal derivatives in both amphioxus (Fig. 2) and vertebrates (specifically gut derivatives including the vertebrate liver), as 


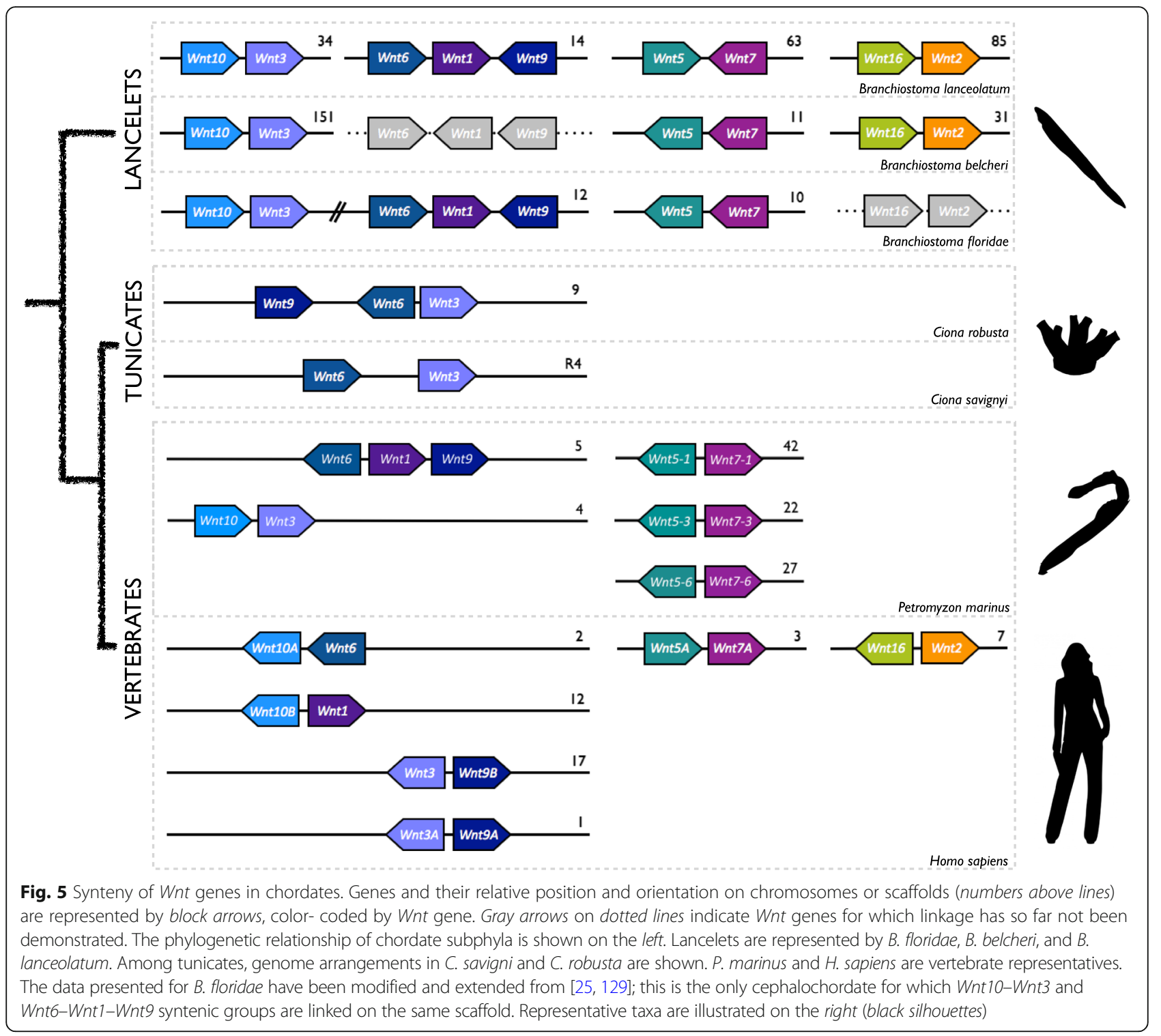

well as in the gill slits, the vertebrate homologs of amphioxus pharyngeal arches, and in the amphioxus cerebral vesicle and the brain of vertebrates [70-73], while to our knowledge, only partial expression data have been documented for Wnt9 orthologs in a colonial ascidian [33]. Finally, shared expression domains are observed for Wnt10 and Wnt16 in the neurectoderm, Wnt16 in somites, and Wnt5, Wnt3, Wnt8, and possibly Wnt11 in the tailbud (Additional file 1: Figure S3 and associated references). Globally, comparative analyses suggest a limited conservation in the expression patterns of orthologous Wnt subfamiles in the three chordate subphyla.

\section{Function shuffling among Wnt paralogs}

In vertebrates, expression of $W n t 1$ is essential for proper anteriorposterior axial patterning of the brain and specification of particular neuronal populations (the "mid-hindbrain organizer"), in some cases functioning redundantly with other Wnt genes [74]. In amphioxus, no Wnt1 expression has been observed in the anterior neuroectoderm or the cerebral vesicle ([38] and this study). However, we have identified a different ligand, $W n t 2$, with expression in the developing cerebral vesicle at mid-neurula stages, which is compatible with a role of amphioxus Wnt2 in cerebral vesicle/hindbrain patterning. Other Wnt genes, including Wnt3, Wnt5, Wnt7, Wnt8, Wnt9, WntA, and Wnt16, are also turned on in the amphioxus brain between neurulation and larval stages (reviewed in [40] and this study). These results are consistent with the unexpectedly complex genoarchitecture in the amphioxus neural tube that is conserved with vertebrates [42] and highlights events of "function 
shuffling" [9] among Wnt paralogs during chordate evolution. Other remarkable examples of function shuffling can be found in the notochord, one of the defining synapomorphies of all chordates. Besides Wnt5 and Wnt11, which are near-ubiquitously expressed and may play more general functions (perhaps in cell movement or polarity) across chordates, Wnt2 is the only paralog expressed in the amphioxus notochord, while chick Wnt16 (and maybe Xenopus Wnt4 and Wnt8 according to Xenbase data) is expressed in the vertebrate structure (Fig. 2; reviewed in Additional file 1: Figure S3). In contrast, Wnt5 in C. robusta and the Wnt-5 $\alpha$ paralog in $H$. roretzi are the only Wnt genes so far identified with expression in the asicidian notochord [26, 31, 75]. Similar examples of Wnt function shuffling are observed in early mesodermal derivatives (e.g., early paraxial mesoderm or somites), which express Wnt10 in amphioxus (this work) but Wnt3 in both vertebrates and ascidians (Fig. 2; reviewed in Additional file 1: Figure S3).

Comparison of the development of the posterior pole of the embryo in all three subphyla reveals a complex scenario in which a variable number of Wnt subfamilies take part in different species. While in ascidians, Wnt5 seems to be the only ligand determining early posteriority in the primary axis, in amphioxus our study reveals a highly redundant posterior Wnt expression system involving at least eight out of the 13 subfamilies (i.e., $W n t 1,8,11$, and 3 surrounding the blastopore during gastrulation, plus Wnt4, 5, 16, and 6 in the most caudal part of the embryo later during neurulation and larval stages). In vertebrates, interestingly, while some species (similarly to ascidians) use a reduced number of Wnt ligands for determing early posteriority (e.g., Wnt8a in zebrafish [76], Wnt11 (and Wnt5) in Xenopus [77, 78], and Wnt3 in mouse [79] (reviewed in [11]), other species such as chicken show a redundant posterior Wnt system, more similarly to amphioxus (e.g., [80, 81]; Additional file 1: Figure S3 and associated references). If the ancestral chordate relied on a simple Wnt system for determing posteriority, extensive Wnt function shuffling occurred during the evolution of the cephalochordate lineage as well as some vertebrate species such as chicken, recruiting other Wnt subfamilies for this posterior signaling role. Evidence from the direct-developing hemichordate Saccoglossus kowalevski further corroborates the idea that posterior Wnt flexibility is a common occurrence during evolution, with a different but partially shared combination of Wnt genes showing blastoporal expression during gastrulation (Wnt1, Wnt3, Wnt4, Wnt6, and Wnt16) [82]. It seems, therefore, that providing $\beta$-catenin is asymmetrically localized (along the axis or in dividing daughter cells), then which particular Wnt ligands act upstream, or how they are spatially organized relative to one another, may not be particularly important [13], making the Wnt system one of the gene families most prone to function shuffling so far described. Importantly, the extensive events of function shuffling that occurred during Wnt evolution challenge the notion of establishing homologies simply based on the expression of orthologous genes and highlight the need to consider these events when analyzing cases of deep homology.

\section{Wnt expression domains absent in amphioxus but present in other chordates}

Different Wnt expression domains have been observed at different stages of germline formation and gonadogenesis in Olfactores, such as Wnt5 in two ascidian species and mouse, Wnt4 and Wnt8 in zebrafish and mouse, Wnt1 and Wnt3 in chick, and Wnt11 in Xenopus (Additional file 1: Figure S3 and associated references), while no evidence has been found suggesting any specific Wnt expression in cephalochordate primordial germ cells (PGCs) or the germline (this work and [46, 67, 83, 84]; reviewed in [49]). Similarly, the mesodermal cardiac-related expression domain of Wnt9 in Olfactores-i.e., the heart endocardium of vertebrates [85] and the epithelial walls of the vasculature of the colonial ascidian B.schlosseri [33] - is not paralleled by any Wht paralog in amphioxus. Moreover, in vertebrates, many Wnt genes are expressed in placodal derivatives and neural crest (Additional file 1: Figure S3 and associated references), and complex modulation of Wnt signals both within ectoderm and from other tissues is required for their specification and later differentiation [86-88]. In amphioxus, none of the ectodermal Wnt domains seem to be compatible with the presence of placode-like structures, which supports the notion that placodes may have been an evolutionary innovation of Olfactores [89-91], similar to migratory cells with neural crest-like properties [92]. It seems, therefore, that the appearance of important functional novelties during chordate diversification-e.g., germline, heart or placode development-were accompanied by new expression domains and functions of $\mathrm{Wht}$ genes.

\section{Evolution of WntA: another new mouth?}

Our work demonstrates the presence of WntA orthologs in both cephalochordates and urochordates, suggesting that its absence in vetebrates is likely due to a specific gene loss in this lineage. Our expression analyses reveal WntA function may be linked to mouth development in amphioxus, since it is clearly expressed in the region where the mouth will open at neurula stages, and around the periphery of the opening mouth in late larvae. A role for Wnt signaling in cephalochordate mouth formation may be further supported by the expression of Wnt antagonist $D k k 1 / 2 / 4$ in the region in which the dissolution of basal laminae and mouth perforation occur [56].

After the dorso-ventral inversion of chordates (i.e., chordates are dorsoventrally inverted relative to non-chordates), 
the chordate mouth shifted from its now dorsal position [93], implying that chordates evolved a new means of mouth formation. Two possible evolutionary scenarios have been proposed for the origin of the amphioxus mouth, which would have had different consequences on the evolution of WntA. In the first scenario, the amphioxus mouth would share its evolutionary origins with the ambulacrarian coelomic pore-canal [56]. In this case, the absence of WntA expression associated with pore-canal formation in Parentrotus lividus [94] may suggest that WntA function was co-opted in the cephalochordate lineage (or secondarily lost in sea urchin). In the second scenario, the amphioxus mouth would represent a specialized gill slit [95] supported by the fact that both structures utilize Wnt (now including WntA), Fgf, and Hh signaling pathways for their formation $[41,96,97]$, and that uncoupling of the gene regulatory network for mouth formation from the blastopore could be key deuterostome innovations. The expression of WntA in hemichordates is of particular relevance for discriminating between these hypotheses. Although evidence points to a conserved pharyngeal transcriptional network in deuterostomes [98], the expression patterns reported for WntA in $S$. kowalveskii are for stages too early to properly evaluate a putative conserved role in gill slit (or mouth) formation [82].

Regarding a role for WntA in ascidian mouth development, it should be noted that Olfactores and amphioxus primary mouths may not be homologous structures [56, 99]. To open a new mouth, Olfactores developed an anterior placode or stomodaeum, whereas amphioxus utilized an alternative system probably owing to its inability to form placodes [100]. With an alternative mode to open a mouth, Olfactores no longer needed $W n t A$ for this purpose, which might favor its loss in vertebrates and redeployment in urochordates. The dorsal-ventral inversion hypothesis, besides postulating changes in mouth formation mechanisms, proposes associated changes in brain architecture, which may have further relaxed constraints on WntA (and other Wnt) gene expression in this structure in different chordate lineages. Losses or redeployments of WntA have indeed been frequent during evolution. WntA has been lost in different species of arthropods, annelids, platyhelminthes and cnidarians [8], or used in a variety of conserved or novel structures and processes in different prototostome species [21, 101-104]. WntA evolution illustrates, therefore, the versatility of Wnt signaling in controlling diverse biological processes in metazoans.

\section{Functional diversification and loss of Wnt signaling during animal evolution}

Function shuffling has significant consequences because it makes it difficult to predict biological function from orthology, challenging the so-called "orthology-function conjecture" (reviewed in [105]). This consequence is supported by the divergent expression patterns we observe here for orthologous chordate Wnt genes. Far from being a specific property of the chordate Wnt family, however, substantial differences have also been reported for Wnt expression in many other animal species, mainly arthopods and annelids [21, 25, 101, 106-110]. A detailed analysis of many Wht genes in different protostome species, for instance, leads to the conclusion that the repertoire of Wnt ligands used during segment addition has evolved differentially among arthropod lineages, that the general role of Wnt8 in regulating posterior development has been altered in annelids [21] and onychophorans [104], and that Wnt5 and Wnt16 orthologs are differentially expressed in annelids [25]. Outside bilaterians, substantial differences in the expression patterns of the ctenophore Mnemiopsis leidyi Wnt genes render difficult comparisons with those of other metazoans, including clades such as cnidarians, placozoans, and poriferans [111].

Finally, the loss of WntA in vertebrates, as well as of a number of Wnt genes in ascidians, illustrate another general feature of Wnt evolution: the "pervasiveness" of the loss of Wnt genes during animal evolution. The loss of Wnt subfamilies in ascidians might have contributed to the morphological diversification of urochordates. Likewise, the loss of Wnt6 in hemipterans has been linked to the loss of maxillary palps in this group of insects [112], while the loss of Wnt2 and Wnt4 in insects [107] might be related with arthropod diversification. Thus, pervasive gene loss accompanied by numerous events of function shuffling appear to be two of the main features that characterize the evolution of the Wnt family not only in chordates but also in all branches of metazoan evolution.

\section{Conclusions}

Up until now, Wnt research has mainly focused on identifying "conserved" biological functions. Here, we argue that essential information can also be gleaned from the analysis of Wnt "differences", many of them derived from events of function shuffling and gene loss. Understanding the biological basis of such differences will help uncover how highly conserved developmental processes-such as axial patterning, germlayer specification, or body segmentation-might be controlled by molecular mechanisms (e.g., Wnt signaling) with remarkable genetic and functional diversity.

\section{Methods}

Genome database searches and phylogenetic analyses

Protein sequences of the Wnt repertoire from vertebrate Homo sapiens, urochordate C. robusta, and cephalochordate $B$. floridae were used as queries in BLASTp and tBLASTn searches in genome databases of selected species: http://amphiencode.github.io/ for B. lanceolatum; http:// 
genome.bucm.edu.cn/lancelet/ for B. belcheri; https://blas t.ncbi.nlm.nih.gov/Blast.cgi for B. floridae; NCBI Sequence Read Archive accession SRX437623 for Asymmetron lucayanum; http://www.aniseed.cnrs.fr/, https://blast.ncbi.nlm.nih. gov/Blast.cgi and http://octopus.obs-vlfr.fr/public/botryllus/ blastbotryllus.php for ascidian species (C. robusta, $C$. savignyi, $P$. fumigata, $P$. mammillata, $H$. roretzi, $H$. aurantium, B. schlosseri, M. occulta, M. oculata, and M. occidentalis); https://genomes.stowers.org/organism/Petromyzon/ marinus and https://www.ensembl.org/Petromyzon_mari nus/Info/Index for P. marinus; and NCBI database for $C$. milii. Orthologies of the non-vertebrate chordate $\mathrm{Wnt}$ were initially assessed by the reciprocal best blast hit (RBBH) approach and corroborated by phylogenetic analyses. Phylogenetic reconstructions were based on ML inferences calculated with PhyML v3.0 and automatic mode of selection of substitution model [113] using protein alignments generated with MUSCLE [114] and CLUSTALX [115] programs and reviewed manually. Accession numbers and protein alignment for phylogenetic tree reconstruction are provided in Additional file 1: Table S1 and Additional file 2, respectively.

Animal collection and gene expression analysis by WMISH C. robusta type $A$ adults were obtained from the National Bio-Resource Project for Ciona (AMED, Japan). $H$. roretzi adults were purchased from fishermen in Aomori and Iwate prefectures, Japan. B. lanceolatum adults were collected in Argelès-sur-Mer, France, and induced to spawn as in [116].

Fragments of Wnt genes were PCR amplified and cloned to synthesize gene-specific riboprobes for $H$. roretzi and B. lanceolatum Wnt genes (Additional file 1: Table S2). For C. robusta, cDNA clones were obtained from the cDNA clone collections [117, 118]. WMISH experiments were performed as previously described in [119] for C. robusta; as in [120] for H. roretzi with minor modifications (the acetylation step was not carried out before prehybridization, and after the antibody incubation the specimens were washed with PBST 12 times, $20 \mathrm{~min}$ each, and stored overnight at $4{ }^{\circ} \mathrm{C}$ ); and as in [41] for B. lanceolatum. NBT/BCIP (Roche) or BMPurple (Roche) were used for the chromogenic reaction.

\section{Comparative studies of expression patterns}

Vertebrate and ascidian Wnt gene expression patterns were identified and cross- and back- referenced using published literature as well as public database searches. These included ANISEED for ascidians species [121, 122] (http://www.aniseed.cnrs.fr/), ZFIN for zebrafish [123] (www.zfin.org), Xenbase for Xenopus [124-126] (http:// www.xenbase.org/, RRID:SCR_003280), Geisha for chick [80] (www.geisha.arizona.edu/geisha/), and the EMAGE gene expression database for mouse [127] (http://www.e mouseatlas.org/emage/). As no such database is currently available for cephalochordates, published literature images were examined by eye only. In all cases, special care was taken to ensure gene name nomenclature in the literature matched our results for Wnt gene assignation. In vertebrates, the expression of paralogs was grouped for ease of comparison across subphyla, under the assumption that both neo- and subfuctionalization events would be adequately represented. Please see Additional file 1: Figure S2 for additional details.

\section{Additional files}

Additional file 1: Figure S1. Evolution of Wnt5 in ascidians. Figure S2. Expression of WntA in two ascidian species. Figure S3. Chordate Wnt expression. Figure S4. Wnt subfamilies in A. lucayanum, P. marinus, and C. milii. Table S1. Chordate Wnt genes analyzed in this study. Table S2. Branchiostoma lanceolatum and Halocynthia roretzi primer and probe sequences. Table S3. Wnt synteny in lancelets ( $B$. lanceolatum, B. belcheri and B. floridae) and vertebrates (H. sapiens and P. marinus). Text S1.Branchiostoma lanceolatum Wnt expression as shown in Fig. 2. Text S2. References for Figure S3. (PDF 11566 kb)

Additional file 2: Wnt sequence alignment for Fig. 1. (FASTA 307 kb) Additional file 3: Wnt sequence alignment for Additional file 1: Figure S4. (FASTA $99 \mathrm{~kb}$ )

\section{Acknowledgements}

The authors thank all team members of the CC and RA laboratories for fruitful discussions on Wnt signaling, gene loss, and evolution. The authors thank the Phallusia and Halocynthia genome sequencing consortia, as well as all other ascidian laboratories for sharing results ahead of their publication. This work was supported by the Branchiostoma lanceolatum genome consortium, which provided access to the Branchiostoma lanceolatum genome sequence. The non-human silhouettes used in Fig. 5 are courtesy of Tom Barton-Owen, with modifications by IS.

\section{Funding}

IS was supported by the European Union Horizon 2020 research and innovation programme under grant agreement numbers 654428 ("CORBEL"). HN was supported by Grants in Aid from The Japan Society for The Promotion of Science $(22370078,15 \mathrm{H} 04377)$ and The Ministry of Education, Culture, Sports, Science and Thechnology, Japan $(23112714,25113518)$. KI was supported by a Grant in Aid from the Japan Society for the Promotion of Science (2671 1014). HE was supported by ANR-16-CE12-0008-01 grant from Agence Nationale de la Recherche. CC was supported by BFU2016-80601-P. RA was supported by BIO2015-67358-C2-1-P grant from Ministerio de Economía y Competitividad (Spain). CC and RA were also supported by grants BFU201014875 from Ministerio de Ciencia e Innovación (Spain), and SGR2014-290 and SGR2017-1665 from Generalitat de Catalunya.

\section{Availability of data and materials}

The data that support the findings of this study are available from public databases: http://amphiencode.github.io/ for B. lanceolatum; http://genome.bucm.edu.cn/ lancelet/ for B. belcheri; https://blast.ncbi.nlm.nih.gov/Blast.cgi for B. floridae; NCBI Sequence Read Archive accession SRX437623 for Asymmetron lucayanum; http:// www.aniseed.cnrs.fr/, https://blast.ncbi.nlm.nih.gov/Blast.cgi, and http://octopus.obsvlfr.fr/public/botryllus/blastbotryllus.php for ascidian species (C. robusta, C. savignyi, $P$. fumigata, P. mammillata, H. roretzi, H. aurantium, B. schlosseri, M. occulta, M. oculata, and $M$. occidentalis); https:/genomes.stowers.org/organism/Petromyzon/marinus and https://www.ensembl.org/Petromyzon_marinus/Info/Index for P. marinus; and NCBI database for C. milii. Additional files 1, 2, and 3, including the alignments used for phylogenetic analyses and the accessions numbers of the genes, are available at https://doi.org/10.6084/m9.figshare.6477494 [128].

\section{Authors' contributions}

IS and RA collected all amphioxus Wnt sequences from databases. IS and HE obtained the amphioxus embryos, and IS carried out whole-mount in situ 
hybridization experiments for expression analysis. IS collated all expression data and did the comparative analyses of chordate Wnt genes. JM-S, MD-G, RA, and CC collected all ascidian Wnt sequences from databases. CC and RA performed phylogenetic calculations, with support from JM-S and MD-G, and elaborated the evolutionary inferences. JM-S, Kl, and HN analyzed the expression of ascidian WntA. IS, CC, and RA designed the study and analyzed data. IS, CC, and RA wrote the manuscript with imput from JM-S, $H E$, and HN. IS, JM-S, CC, and RA finalized figures, tables, and text. All authors commented on the manuscript and agreed to its final version.

\section{Ethics approval and consent to participate}

Not applicable.

\section{Competing interests}

The authors declare that they have no competing interests.

\section{Publisher's Note}

Springer Nature remains neutral with regard to jurisdictional claims in published maps and institutional affiliations.

\section{Author details}

'Biomedical Sciences Research Complex, School of Biology, University of St Andrews, North Haugh, St Andrews KY16 9ST, Scotland, UK. ${ }^{2}$ Scottish Oceans Institute, School of Biology, University of St Andrews, East Sands, St Andrews KY16 8LB, Scotland, UK. ${ }^{3}$ Departament de Genètica, , Microbiologia i Estadística, and Institut de Recerca de la Biodiversitat (IRBio), Universitat de Barcelona, Barcelona, Spain. ${ }^{4}$ Department of Biological Sciences, Graduate School of Science, Osaka University, Toyonaka, Osaka 560-0043, Japan. ${ }^{5}$ Sorbonne Universités, UPMC Univ Paris 06, CNRS, Biologie Intégrative des Organismes Marins (BIOM), Observatoire Océanologique, F-66650 Banyuls/ Mer, France.

\section{Received: 11 January 2018 Accepted: 22 June 2018}

\section{Published online: 25 July 2018}

\section{References}

1. Paps J, Holland PWH. Reconstruction of the ancestral metazoan genome reveals an increase in genomic novelty. Nat Commun. 2018;9:1730.

2. Suga H, Chen Z, de Mendoza A, Sebe-Pedros A, Brown MW, Kramer E, Carr M, Kerner $\mathrm{P}$, Vervoort M, Sanchez-Pons $\mathrm{N}$, et al. The Capsaspora genome reveals a complex unicellular prehistory of animals. Nat Commun. 2013;4:2325.

3. Taylor JS, Raes J. Duplication and divergence: the evolution of new genes and old ideas. Annu Rev Genet. 2004;38:615-43.

4. Cañestro C, Albalat R, Irimia M, Garcia-Fernandez J. Impact of gene gains, losses and duplication modes on the origin and diversification of vertebrates. Semin Cell Dev Biol. 2013;24:83-94.

5. Cañestro C, Catchen JM, Rodríguez-Marí A, Yokoi H, Postlethwait JH. Consequences of lineage-specific gene loss on functional evolution of surviving paralogs: ALDH1A and retinoic acid signaling in vertebrate genomes. PLoS Genet. 2009;5:e1000496.

6. O'Malley MA, Wideman JG, Ruiz-Trillo I. Losing complexity: the role of simplification in macroevolution. Trends Ecol Evol. 2016;31:608-21.

7. Olson MV. When less is more: gene loss as an engine of evolutionary change. Am J Hum Genet. 1999;64:18-23.

8. Albalat R, Cañestro C. Evolution by gene loss. Nat Rev Genet. 2016;17:379-91.

9. McClintock JM, Carlson R, Mann DM, Prince VE. Consequences of Hox gene duplication in the vertebrates: an investigation of the zebrafish Hox paralogue group 1 genes. Development. 2001;128:2471-84.

10. Holstein TW. The evolution of the Wnt pathway. Cold Spring Harb Perspect Biol. 2012;4:a007922.

11. Loh KM, van Amerongen R, Nusse R. Generating cellular diversity and spatial form: Wnt signaling and the evolution of multicellular animals. Dev Cell. 2016;38:643-55.

12. Guder C, Philipp I, Lengfeld T, Watanabe H, Hobmayer B, Holstein TW. The Wnt code: cnidarians signal the way. Oncogene. 2006;25:7450-60.

13. Petersen CP, Reddien PW. Wnt signaling and the polarity of the primary body axis. Cell. 2009;139:1056-68.

14. Niehrs C. The complex world of WNT receptor signalling. Nat Rev Mol Cell Biol. 2012;13:767-79.
15. Rigo-Watermeier T, Kraft B, Ritthaler M, Wallkamm V, Holstein T, Wedlich D. Functional conservation of Nematostella Wnts in canonical and noncanonical Wnt-signaling. Biol Open. 2012;1:43-51.

16. Andre P, Song H, Kim W, Kispert A, Yang Y. Wnt5a and Wnt11 regulate mammalian anterior-posterior axis elongation. Development. 2015;142:1516-27.

17. Kraus $Y$, Aman A, Technau U, Genikhovich G. Pre-bilaterian origin of the blastoporal axial organizer. Nat Commun. 2016;7:11694.

18. van Amerongen R, Fuerer $C$, Mizutani M, Nusse R. Wnt5a can both activate and repress Wnt/beta-catenin signaling during mouse embryonic development. Dev Biol. 2012;369:101-14.

19. Kusserow A, Pang K, Sturm C, Hrouda M, Lentfer J, Schmidt HA, Technau U, von Haeseler A, Hobmayer B, Martindale MQ, Holstein TW. Unexpected complexity of the Wnt gene family in a sea anemone. Nature. 2005;433:156-60.

20. Borisenko I, Adamski M, Ereskovsky A, Adamska M. Surprisingly rich repertoire of Wht genes in the demosponge Halisarca dujardini. BMC Evol Biol. 2016;16:123.

21. Janssen R, Le Gouar M, Pechmann M, Poulin F, Bolognesi R, Schwager EE, Hopfen C, Colbourne JK, Budd GE, Brown SJ, et al. Conservation, loss, and redeployment of Wnt ligands in protostomes: implications for understanding the evolution of segment formation. BMC Evol Biol. 2010;10:374.

22. Murat S, Hopfen C, McGregor AP. The function and evolution of Wnt genes in arthropods. Arthropod Struct Dev. 2010;39:446-52.

23. Rentzsch F, Technau U. Genomics and development of Nematostella vectensis and other anthozoans. Curr Opin Genet Dev. 2016;39:63-70.

24. Prud'homme B, Lartillot N, Balavoine G, Adoutte A, Vervoort M. Phylogenetic analysis of the Wnt gene family. Insights from lophotrochozoan members. Curr Biol. 2002;12:1395.

25. Cho SJ, Valles Y, Giani VC Jr, Seaver EC, Weisblat DA. Evolutionary dynamics of the wnt gene family: a lophotrochozoan perspective. Mol Biol Evol. 2010; 27:1645-58.

26. Sasakura $Y$, Ogasawara M, Makabe KW. HrWnt-5: a maternally expressed ascidian Wnt gene with posterior localization in early embryos. Int J Dev Biol. 1998;42:573-9.

27. Sasakura Y, Makabe KW. Ascidian Wnt-7 gene is expressed exclusively in the tail neural tube of tailbud embryos. Dev Genes Evol. 2000;210:641-3.

28. Miya $\mathrm{T}$, Nishida $\mathrm{H}$. Isolation of CDNA clones for mRNAs transcribed zygotically during cleavage in the ascidian, Halocynthia roretzi. Dev Genes Evol. 2002;212:30-7.

29. Hino K, Satou Y, Yagi K, Satoh N. A genomewide survey of developmentally relevant genes in Ciona intestinalis. VI. Genes for Wnt, TGFbeta, hedgehog and JAKJSTAT signaling pathways. Dev Genes Evol. 2003;213:264-72.

30. Hotta K, Takahashi H, Ueno N, Gojobori T. A genome-wide survey of the genes for planar polarity signaling or convergent extension-related genes in Ciona intestinalis and phylogenetic comparisons of evolutionary conserved signaling components. Gene. 2003;317:165-85.

31. Imai KS, Hino K, Yagi K, Satoh N, Satou Y. Gene expression profiles of transcription factors and signaling molecules in the ascidian embryo: towards a comprehensive understanding of gene networks. Development. 2004:131:4047-58.

32. Rosner A, Alfassi G, Moiseeva E, Paz G, Rabinowitz C, Lapidot Z, Douek J, Haim A, Rinkevich B. The involvement of three signal transduction pathways in botryllid ascidian astogeny, as revealed by expression patterns of representative genes. Int J Dev Biol. 2014;58:677-92.

33. Di Maio A, Setar L, Tiozzo S, De Tomaso AW. Wht affects symmetry and morphogenesis during post-embryonic development in colonial chordates. Evodevo. 2015;6:17.

34. Schubert M, Holland LZ, Holland ND. Characterization of two amphioxus Wnt genes (AmphiWnt4 and AmphiWnt7b) with early expression in the developing central nervous system. Dev Dyn. 2000;217:205-15.

35. Schubert M, Holland LZ, Holland ND. Characterization of an amphioxus wnt gene, AmphiWnt11, with possible roles in myogenesis and tail outgrowth. Genesis. 2000;27:1-5.

36. Schubert M, Holland LZ, Holland ND, Jacobs DK. A phylogenetic tree of the Wnt genes based on all available full-length sequences, including five from the cephalochordate amphioxus. Mol Biol Evol. 2000;17:1896-903.

37. Schubert M, Holland LZ, Panopoulou GD, Lehrach H, Holland ND. Characterization of amphioxus AmphiWnt8: insights into the evolution of patterning of the embryonic dorsoventral axis. Evol Dev. 2000;2:85-92.

38. Holland LZ, Holland ND, Schubert M. Developmental expression of AmphiWnt1, an amphioxus gene in the Wnt1/wingless subfamily. Dev Genes Evol. 2000;210:522-4. 
39. Schubert M, Holland LZ, Stokes MD, Holland ND. Three amphioxus Wnt genes (AmphiWnt3, AmphiWnt5, and AmphiWnt6) associated with the tail bud: the evolution of somitogenesis in chordates. Dev Biol. 2001; 240:262-73.

40. Bertrand S, Le Petillon Y, Somorjai I, Escriva H. Developmental cell-cell communication pathways in the cephalochordate amphioxus: actors and functions. Int J Dev Biol. 2017;61:697-722.

41. Somorjai I, Bertrand S, Camasses A, Haguenauer A, Escriva H. Evidence for stasis and not genetic piracy in developmental expression patterns of Branchiostoma lanceolatum and Branchiostoma floridae, two amphioxus species that have evolved independently over the course of 200 Myr. Dev Genes Evol. 2008;218:703-13.

42. Albuixech-Crespo B, Lopez-Blanch L, Burguera D, Maeso I, Sanchez-Arrones L, Moreno-Bravo JA, Somorjai I, Pascual-Anaya J, Puelles E, Bovolenta P, et al. Molecular regionalization of the developing amphioxus neural tube challenges major partitions of the vertebrate brain. PLoS Biol. 2017;15:e2001573.

43. Yue JX, Yu JK, Putnam NH, Holland LZ. The transcriptome of an amphioxus, Asymmetron lucayanum, from the Bahamas: a window into chordate evolution. Genome Biol Evol. 2014;6:2681-96.

44. Cañestro C, Albalat R. Transposon diversity is higher in amphioxus than in vertebrates: functional and evolutionary inferences. Brief Funct Genomics. 2012;11:131-41.

45. Louis A, Roest Crollius H, Robinson-Rechavi M. How much does the amphioxus genome represent the ancestor of chordates? Brief Funct Genomics. 2012;11:89-95.

46. Dailey SC, Febrero Planas R, Rossell Espier A, Garcia-Fernàndez J, Somorjai IML. Asymmetric distribution of pl10 and bruno2, new members of a conserved Core of early germline determinants in cephalochordates. Front Ecol Evol. 2016;3:156.

47. Yong LW, Bertrand S, Yu JK, Escriva H, Holland ND. Conservation of BMP2/4 expression patterns within the clade Branchiostoma (amphioxus): resolving interspecific discrepancies. Gene Expr Patterns. 2017;25-26:71-5.

48. Paps J, Holland PW, Shimeld SM. A genome-wide view of transcription factor gene diversity in chordate evolution: less gene loss in amphioxus? Brief Funct Genomics. 2012:11:177-86.

49. Somorjai l, et al. Amphioxus regeneration: evolutionary and biomedical implications. Int J Dev Biol. 2017;61:689-96.

50. Cañestro C, Albalat R, Hjelmqvist L, Godoy L, Jornvall H, Gonzalez-Duarte R. Ascidian and amphioxus Adh genes correlate functional and molecular features of the $\mathrm{ADH}$ family expansion during vertebrate evolution. J Mol Evol. 2002;54:81-9.

51. Nohara M, Nishida M, Nishikawa T. New complete mitochondrial DNA sequence of the lancelet Branchiostoma lanceolatum (Cephalochordata) and the identity of this species' sequences. Zool Sci. 2005;22:671-4.

52. Kon T, Nohara M, Yamanoue $Y$, Fujiwara $Y$, Nishida M, Nishikawa T. Phylogenetic position of a whale-fall lancelet (Cephalochordata) inferred from whole mitochondrial genome sequences. BMC Evol Biol. 2007;7:127.

53. Igawa T, Nozawa M, Suzuki DG, Reimer JD, Morov AR, Wang Y, Henmi Y, Yasui K. Evolutionary history of the extant amphioxus lineage with shallowbranching diversification. Sci Rep. 2017;7:1157.

54. Felsenstein J. Cases in which parsimony or compatibility methods will be positively misleading. Syst Zool. 1978;27:401-10.

55. Holland LZ, Holland ND. A revised fate map for amphioxus and the evolution of axial patterning in chordates. Integr Comp Biol. 2007;47:360-72.

56. Kaji T, Reimer JD, Morov AR, Kuratani S, Yasui K. Amphioxus mouth after dorso-ventral inversion. Zoological Lett. 2016;2:2.

57. Pascual-Anaya J, Albuixech-Crespo B, Somorjai IM, Carmona R, Oisi Y, Alvarez S, Kuratani S, Munoz-Chapuli R, Garcia-Fernandez J. The evolutionary origins of chordate hematopoiesis and vertebrate endothelia. Dev Biol. 2013;375:182-92.

58. Garcia-Fernàndez J, Holland PW. Archetypal organization of the amphioxus Hox gene cluster. Nature. 1994;370:563-6.

59. Holland LZ, Albalat R, Azumi K, Benito-Gutierrez E, Blow MJ, Bronner-Fraser M, Brunet F, Butts T, Candiani S, Dishaw $L$, et al. The amphioxus genome illuminates vertebrate origins and cephalochordate biology. Genome Res. 2008;18:1100-11.

60. Cañestro C, Postlethwait JH, Gonzàlez-Duarte R, Albalat R. Is retinoic acid genetic machinery a chordate innovation? Evol Dev. 2006;8:394-406.

61. Albalat R. The retinoic acid machinery in invertebrates: ancestral elements and vertebrate innovations. Mol Cell Endocrinol. 2009;313:23-35.
62. Albalat R, Brunet F, Laudet V, Schubert M. Evolution of retinoid and steroid signaling: vertebrate diversification from an amphioxus perspective. Genome Biol Evol. 2011;3:985-1005.

63. D'Aniello S, Irimia M, Maeso I, Pascual-Anaya J, Jimenez-Delgado S, Bertrand S, Garcia-Fernandez J. Gene expansion and retention leads to a diverse tyrosine kinase superfamily in amphioxus. Mol Biol Evol. 2008;25:1841-54.

64. Albalat R. Evolution of DNA-methylation machinery: DNA methyltransferases and methyl-DNA binding proteins in the amphioxus Branchiostoma floridae. Dev Genes Evol. 2008;218:691-701.

65. Albalat R, Marti-Solans J, Cañestro C. DNA methylation in amphioxus: from ancestral functions to new roles in vertebrates. Brief Funct Genomics. 2012; 11:142-55.

66. Oulion S, Bertrand S, Escriva H. Evolution of the FGF gene family. Int J Evol Biol. 2012;2012:298147

67. Zhang QJ, Luo YJ, Wu HR, Chen YT, Yu JK. Expression of germline markers in three species of amphioxus supports a preformation mechanism of germ cell development in cephalochordates. Evodevo. 2013:4:17.

68. Blader P, Strahle U, Ingham PW. Three Wnt genes expressed in a wide variety of tissues during development of the zebrafish, Danio rerio: developmental and evolutionary perspectives. Dev Genes Evol. 1996;206:3-13.

69. Yagi K, Satoh N, Satou Y. Identification of downstream genes of the ascidian muscle determinant gene ci-macho1. Dev Biol. 2004;274:478-89.

70. Curtin E, Hickey G, Kamel G, Davidson AJ, Liao EC. Zebrafish wnt9a is expressed in pharyngeal ectoderm and is required for palate and lower jaw development. Mech Dev. 2011;128:104-15.

71. Quinlan R, Graf M, Mason I, Lumsden A, Kiecker C. Complex and dynamic patterns of Wnt pathway gene expression in the developing chick forebrain. Neural Dev. 2009:4:35

72. Cox AA, Jezewski PA, Fang PK, Payne-Ferreira TL. Zebrafish Wnt9a,9b paralog comparisons suggest ancestral roles for Wnt9 in neural, oral-pharyngeal ectoderm and mesendoderm. Gene Expr Patterns. 2010;10:251-8.

73. Zhang B, Tran U, Wessely O. Expression of Wht signaling components during Xenopus pronephros development. PLoS One. 2011;6:e26533.

74. Lekven AC, Buckles GR, Kostakis N, Moon RT. Wnt1 and wnt10b function redundantly at the zebrafish midbrain-hindbrain boundary. Dev Biol. 2003; 254:172-87.

75. Niwano T, Takatori N, Kumano G, Nishida H. Wnt5 is required for notochord cell intercalation in the ascidian Halocynthia roretzi. Biol Cell. 2009;101:645-59.

76. Lu Fl, Thisse C, Thisse B. Identification and mechanism of regulation of the zebrafish dorsal determinant. Proc Natl Acad Sci U S A. 2011;108:15876-80.

77. Tao Q, Yokota C, Puck H, Kofron M, Birsoy B, Yan D, Asashima M, Wylie CC, Lin $\mathrm{X}$, Heasman J. Maternal wnt11 activates the canonical wnt signaling pathway required for axis formation in Xenopus embryos. Cell. 2005;120: 857-71.

78. Cha SW, Tadjuidje E, Tao Q, Wylie C, Heasman J. Wnt5a and Wnt11 interact in a maternal Dkk1-regulated fashion to activate both canonical and noncanonical signaling in Xenopus axis formation. Development. 2008;135: 3719-29.

79. Liu P, Wakamiya M, Shea MJ, Albrecht U, Behringer RR, Bradley A. Requirement for Wnt3 in vertebrate axis formation. Nat Genet. 1999;22:361-5.

80. Antin PB, Yatskievych TA, Davey S, Darnell DK. GEISHA: an evolving gene expression resource for the chicken embryo. Nucleic Acids Res. 2014;42: D933-7.

81. Martin A, Maher S, Summerhurst K, Davidson D, Murphy P. Differential deployment of paralogous Wnt genes in the mouse and chick embryo during development. Evol Dev. 2012;14:178-95.

82. Darras S, Fritzenwanker JH, Uhlinger KR, Farrelly E, Pani AM, Hurley IA, Norris RP, Osovitz M, Terasaki M, Wu M, et al. Anteroposterior axis patterning by early canonical Wnt signaling during hemichordate development. PLoS Biol. 2018;16:e2003698

83. Wu HR, Chen YT, Su YH, Luo YJ, Holland LZ, Yu JK. Asymmetric localization of germline markers vasa and Nanos during early development in the amphioxus Branchiostoma floridae. Dev Biol. 2011;353:147-59.

84. Yue JX, Li KL, Yu JK. Discovery of germline-related genes in cephalochordate amphioxus: a genome wide survey using genome annotation and transcriptome data. Mar Genomics. 2015;24(Pt 2):147-57.

85. Person AD, Garriock RJ, Krieg PA, Runyan RB, Klewer SE. Frzb modulates Wnt-9a-mediated beta-catenin signaling during avian atrioventricular cardiac cushion development. Dev Biol. 2005;278:35-48.

86. Garcia-Castro MI, Marcelle C, Bronner-Fraser M. Ectodermal Wnt function as a neural crest inducer. Science. 2002;297:848-51. 
87. Steventon B, Mayor R, Streit A. Neural crest and placode interaction during the development of the cranial sensory system. Dev Biol. 2014;389:28-38.

88. Ohyama T, Mohamed OA, Taketo MM, Dufort D, Groves AK. Wht signals mediate a fate decision between otic placode and epidermis. Development 2006;133:865-75

89. Bassham S, Postlethwait JH. The evolutionary history of placodes: a molecular genetic investigation of the larvacean urochordate Oikopleura dioica. Development. 2005;132:4259-72.

90. Manni L, Lane NJ, Joly JS, Gasparini F, Tiozzo S, Caicci F, Zaniolo G, Burighel P. Neurogenic and non-neurogenic placodes in ascidians. J Exp Zoolog B Mol Dev Evol. 2004;302:483-504.

91. Schlosser G. From so simple a beginning - what amphioxus can teach us about placode evolution. Int J Dev Biol. 2017;61:633-48.

92. Abitua $P B$, Wagner $E$, Navarrete IA, Levine M. Identification of a rudimentary neural crest in a non-vertebrate chordate. Nature. 2012:492:104-7.

93. Lacalli TC. Basic features of the ancestral chordate brain: a protochordate perspective. Brain Res Bull. 2008;75:319-23.

94. Robert N, Lhomond G, Schubert M, Croce JC. A comprehensive survey of wnt and frizzled expression in the sea urchin Paracentrotus lividus. Genesis. 2014;52:235-50.

95. Ruppert EE. Morphology of Hatschek's nephridium in larval and juvenile stages of Branchiostoma virginiae (cephalochordata). Isr J Zool. 1996;42: S161-82.

96. Bertrand S, Camasses A, Somorjai I, Belgacem MR, Chabrol O, Escande ML, Pontarotti P, Escriva $\mathrm{H}$. Amphioxus FGF signaling predicts the acquisition of vertebrate morphological traits. Proc Natl Acad Sci U S A. 2011;108:9160-5.

97. Shimeld SM, van den Heuvel M, Dawber R, Briscoe J. An amphioxus Gli gene reveals conservation of midline patterning and the evolution of hedgehog signalling diversity in chordates. PLoS One. 2007;2:e864.

98. Gillis JA, Fritzenwanker JH, Lowe CJ. A stem-deuterostome origin of the vertebrate pharyngeal transcriptional network. Proc Biol Sci. 2012;279: 237-46.

99. Christiaen L, Jaszczyszyn Y, Kerfant M, Kano S, Thermes V, Joly JS. Evolutionary modification of mouth position in deuterostomes. Semin Cell Dev Biol. 2007;18:502-11.

100. Meulemans D, Bronner-Fraser M. The amphioxus SoxB family: implications for the evolution of vertebrate placodes. Int J Biol Sci. 2007;3:356-64.

101. Pruitt MM, Letcher EJ, Chou HC, Bastin BR, Schneider SQ. Expression of the wnt gene complement in a spiral-cleaving embryo and trochophore larva. Int J Dev Biol. 2014;58:563-73.

102. Bolognesi R, Farzana L, Fischer TD, Brown SJ. Multiple Wnt genes are required for segmentation in the short-germ embryo of Tribolium castaneum. Curr Biol. 2008;18:1624-9.

103. Hayden L, Schlosser G, Arthur W. Functional analysis of centipede development supports roles for Wnt genes in posterior development and segment generation. Evol Dev. 2015;17:49-62.

104. Hogvall M, Schonauer A, Budd GE, McGregor AP, Posnien N, Janssen R. Analysis of the Wnt gene repertoire in an onychophoran provides new insights into the evolution of segmentation. Evodevo. 2014;5:14

105. Gabaldon T, Koonin EV. Functional and evolutionary implications of gene orthology. Nat Rev Genet. 2013;14:360-6.

106. Bolognesi R, Beermann A, Farzana L, Wittkopp N, Lutz R, Balavoine G, Brown SJ, Schroder R. Tribolium Wnts: evidence for a larger repertoire in insects with overlapping expression patterns that suggest multiple redundant functions in embryogenesis. Dev Genes Evol. 2008;218:193-202.

107. Janssen R, Posnien N. Identification and embryonic expression of Wnt2, Wnt4, Wnt5 and Wnt9 in the millipede Glomeris marginata (Myriapoda: Diplopoda). Gene Expr Patterns. 2014;14:55-61.

108. Constantinou SJ, Pace RM, Stangl AJ, Nagy LM, Williams TA. Wht repertoire and developmental expression patterns in the crustacean Thamnocephalus platyurus. Evol Dev. 2016;18:324-41.

109. Henry JQ, Perry KJ, Wever J, Seaver E, Martindale MQ. Beta-catenin is required for the establishment of vegetal embryonic fates in the nemertean, Cerebratulus lacteus. Dev Biol. 2008;317:368-79.

110. Henry JQ, Perry KJ, Martindale MQ. Beta-catenin and early development in the gastropod, Crepidula fornicata. Integr Comp Biol. 2010;50:707-19.

111. Pang K, Ryan JF, Mullikin JC, Baxevanis AD, Martindale MQ. Genomic insights into Wnt signaling in an early diverging metazoan, the ctenophore Mnemiopsis leidyi. Evodevo. 2010;1:10.

112. Doumpas N, Jekely G, Teleman AA. Wnt6 is required for maxillary palp formation in Drosophila. BMC Biol. 2013;11:104.
113. Guindon S, Dufayard JF, Lefort V, Anisimova M, Hordijk W, Gascuel O. New algorithms and methods to estimate maximum-likelihood phylogenies: assessing the performance of PhyML 3.0. Syst Biol. 2010;59:307-21.

114. Edgar RC. MUSCLE: a multiple sequence alignment method with reduced time and space complexity. BMC Bioinformatics. 2004;5:113.

115. Larkin MA, Blackshields G, Brown NP, Chenna R, McGettigan PA, McWilliam $H$, Valentin F, Wallace IM, Wilm A, Lopez R, et al. Clustal W and Clustal X version 2.0. Bioinformatics (Oxf). 2007;23:2947-8.

116. Fuentes M, Schubert M, Dalfo D, Candiani S, Benito E, Gardenyes J, Godoy L, Moret F, Illas M, Patten I, et al. Preliminary observations on the spawning conditions of the European amphioxus (Branchiostoma lanceolatum) in captivity. J Exp Zoolog B Mol Dev Evol. 2004;302:384-91.

117. Satou Y, Kawashima T, Shoguchi E, Nakayama A, Satoh N. An integrated database of the ascidian, Ciona intestinalis: towards functional genomics. Zool Sci. 2005:22:837-43.

118. Gilchrist MJ, Sobral D, Khoueiry P, Daian F, Laporte B, Patrushev I, Matsumoto J, Dewar K, Hastings KE, Satou Y, et al. A pipeline for the systematic identification of non-redundant full-ORF cDNAs for polymorphic and evolutionary divergent genomes: application to the ascidian Ciona intestinalis. Dev Biol. 2015;404:149-63.

119. Satou Y. Posterior end mark 3 (pem-3), an ascidian maternally expressed gene with localized mRNA encodes a protein with Caenorhabditis elegans MEX-3-like KH domains. Dev Biol. 1999;212:337-50.

120. Wada S, Katsuyama Y, Yasugi S, Saiga H. Spatially and temporally regulated expression of the LIM class homeobox gene Hrlim suggests multiple distinct functions in development of the ascidian, Halocynthia roretzi. Mech Dev. 1995;51:115-26

121. Brozovic M, Martin C, Dantec C, Dauga D, Mendez M, Simion P, Percher M, Laporte B, Scornavacca C, Di Gregorio A, et al. ANISEED 2015: a digital framework for the comparative developmental biology of ascidians. Nucleic Acids Res. 2016;44:D808-18.

122. Brozovic M, Dantec C, Dardaillon J, Dauga D, Faure E, Gineste M, Louis A, Naville M, Nitta KR, Piette J, et al. ANISEED 2017: extending the integrated ascidian database to the exploration and evolutionary comparison of genome-scale datasets. Nucleic Acids Res. 2018;46:D718-D725.

123. Howe DG, Bradford YM, Conlin T, Eagle AE, Fashena D, Frazer K, Knight J, Mani P, Martin R, Moxon SA, et al. ZFIN, the zebrafish model organism database: increased support for mutants and transgenics. Nucleic Acids Res. 2013;41:D854-60

124. Bowes JB, Snyder KA, Segerdell E, Jarabek CJ, Azam K, Zorn AM, Vize PD Xenbase: gene expression and improved integration. Nucleic Acids Res. 2010;38:D607-12

125. Karpinka JB, Fortriede JD, Burns KA, James-Zorn C, Ponferrada VG, Lee J, Karimi K, Zorn AM, Vize PD. Xenbase, the Xenopus model organism database; new virtualized system, data types and genomes. Nucleic Acids Res. 2015:43:D756-63.

126. James-Zorn C, Ponferrada VG, Burns KA, Fortriede JD, Lotay VS, Liu Y, Brad Karpinka J, Karimi K, Zorn AM, Vize PD. Xenbase: Core features, data acquisition, and data processing. Genesis. 2015;53:486-97.

127. Richardson L, Venkataraman S, Stevenson P, Yang Y, Moss J, Graham L, Burton N, Hill B, Rao J, Baldock RA, Armit C. EMAGE mouse embryo spatial gene expression database: 2014 update. Nucleic Acids Res. 2014;42:D835-44.

128. Somorjai IML, Martí-Solans J, Diaz-Gracia M, Nishida H, Imai KS, Escrivà H, Cañestro C, Albalat R. Wnt evolution and function shuffling in liberal and conservative chordate genomes. Data set 1. figshare. doi:https://doi.org/10. 6084/m9.figshare.6477494

129. Putnam NH, Butts $T$, Ferrier DE, Furlong RF, Hellsten U, Kawashima $T$, Robinson-Rechavi M, Shoguchi E, Terry A, Yu JK, et al. The amphioxus genome and the evolution of the chordate karyotype. Nature. 2008;453: 1064-71. 